\title{
Microstructure observations of the summer-to-winter destratification at a coastal site in the Gulf of Naples.
}

\author{
Florian Kokoszka ${ }^{1}$, Fabio Conversano ${ }^{1}$, Daniele Iudicone $^{1}$, Bruno Ferron $^{2}$, \\ Pascale Bouruet-Aubertot ${ }^{3}$, Justine Mc Millan ${ }^{4}$

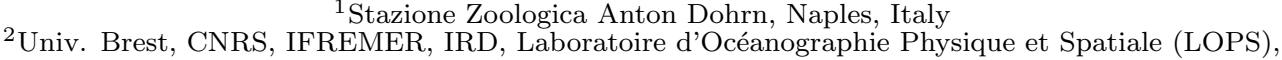 \\ IUEM, Plouzané, France \\ ${ }^{3}$ Sorbonne Université (UPMC, Univ Paris 06)-CNRS-IRD-MNHN, LOCEAN, Paris, France \\ ${ }^{4}$ Rockland Scientific International Inc., Victoria, Canada
}

\section{Key Points:}

- The seasonal cycle of the dissipation rates of turbulent kinetic energy $\epsilon$ at a midlatitude coastal site is presented, covering the destratification period.

- A progressive deepening of the mixed layer depth was observed from September to December, finally extending to the whole water-column at the beginning of winter.

- The statistics of $\epsilon$ depend upon the time of the year and the position with respect to the mixed layer depth. A seasonal increase in storminess is correlated with an increase in intermittency of the turbulence in the mixed layer.

- We observed a quadratic relation between kurtosis and skewness for the statistics of $\epsilon$.

- A co-location of patches of higher $\epsilon$ with the shear maxima of the two first baroclinic modes suggests internal waves activity plays a role in the setting the mixing intensity despite the lack of tidal forcing.

- The low-passed microstructure shear distribution seems to support this hypothesis despite possible signal contaminations.

- The variability of the stratification is ruled by several physical processes, including freshwater inputs from land, whose importance varies with the seasons; this succession has to be considered when studying the impact of climate change upon the stratification. 





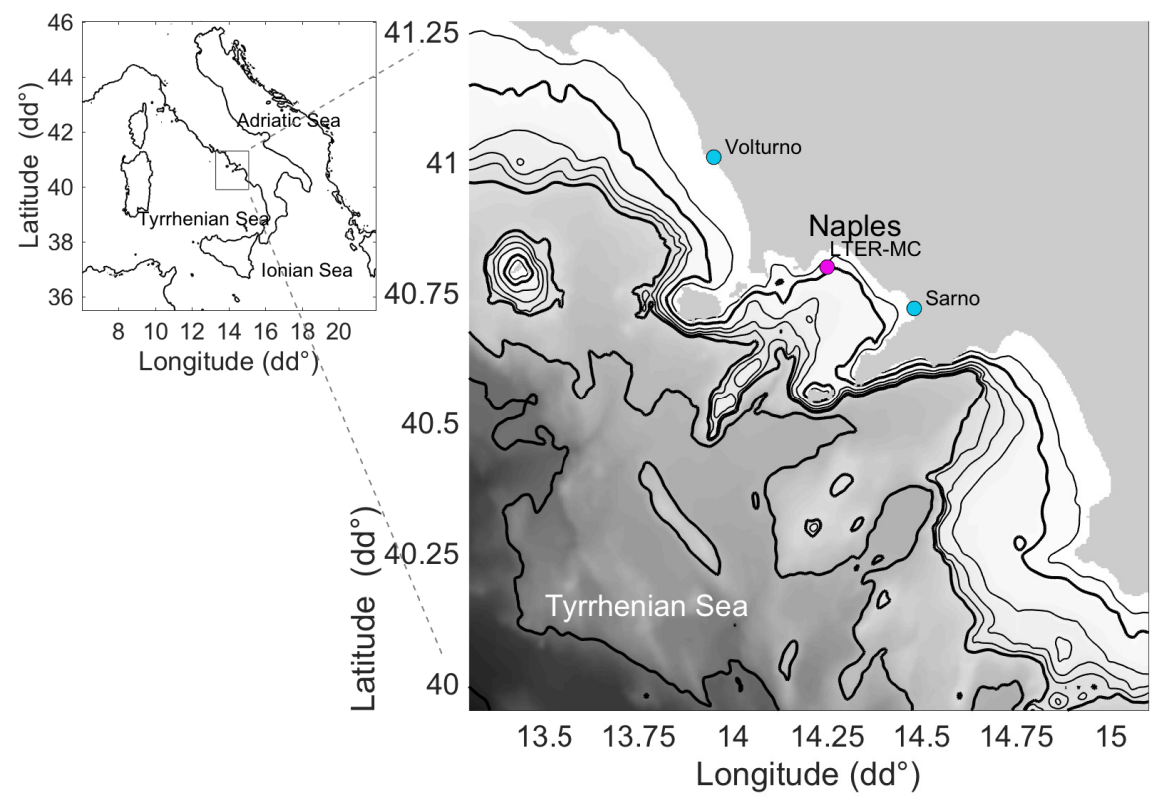

Figure 1: Bathymetry of the Gulf of Naples (GEBCO grid [GEBCO, 2020]) along the Tyrrhenian Sea in the Mediterranean basin). The 75m-deep LTER-MC coastal sampling site $\left(14.25^{\circ} \mathrm{E}, 40.80^{\circ} \mathrm{N}\right)$ is located by the pink dot. Volturno and Sarno's river mouths are shown in blue. Thin lines indicate the 50,200, 300 and $400 \mathrm{~m}$ isobaths, thick ones indicate the 100, 500, 1000 and $2000 \mathrm{~m}$ isobaths.

the VMP-250 was used for this analysis. Combining the vertical gradients and their signs allows the identification of stability regimes, that can be defined from the ratio $R_{\rho}=$ $(\alpha d \theta / d z) /(\beta d S / d z)$ where $\alpha=-\rho^{-1}(d \rho / d \theta)$ is the thermal expansion coefficient, $\beta=$ $\rho^{-1}(d \rho / d S)$ is the haline contraction coefficient, where $d \rho / d z$ and $d \theta / d z$ are the vertical gradients of density and temperature, respectively. This ratio is used to calculate the Turner angles $\left(^{\circ}\right) T u=\arctan \left(\left(1+R_{\rho}\right) /\left(1-R_{\rho}\right)\right)$ (Ruddick [1983]). The value of the Turner angle defines various stability regimes. A diffusive convection regime (e.g., fresh cold layers over warm salty layer) arises when $-90^{\circ}<T u<-45^{\circ}$. A double-diffusive regime (e.g., salty warm layer over cold fresh layer) arises when $45^{\circ}<T u<90^{\circ}$. Within each of these regimes, the instability is higher when $|T u|$ is close to 90 degrees. A stable regime occurs when $|T u|<45^{\circ}$, whereas a gravitationally unstable regime occurs when $|T u|>90^{\circ}$.

\subsection{Heat fluxes, winds and precipitations}

Surface heat fluxes (latent and sensible, with net solar and thermal radiation, in $\mathrm{W} \mathrm{m}{ }^{-2}$ ), wind velocities $\left(U_{10}\right.$ and $V_{10}, \mathrm{~m} \mathrm{~s}^{-1}$ ), evaporation $E$ and precipitation rates $P$ $\left(\mathrm{mm} \mathrm{d}^{-1}\right)$ were extracted from the ERA5 re-analysed product provided by Copernicus (ERA5(C3S) [2017]). The closest grid-point was selected from the LTER-MC geographical position $\left(14.25^{\circ} \mathrm{E}\right.$ and $\left.40.80^{\circ} \mathrm{N}\right)$, with a 6 -hour temporal resolution, over the whole period. We used those values to infer the Monin-Obukhov length scale $\left(L_{M O}\right)$ (Obukhov [n.d.], Obukhov [1971]), a critical length scale describing the depth at which the turbulence is generated more by wind shear than buoyancy forcings, defined as $L_{M O}=u_{*}^{3} / \kappa B$ $(m)$. Here $u_{*}$ is the friction velocity of the wind $\left(\mathrm{m} \mathrm{s}^{-1}\right), \kappa$ the von Karman's constant (here 0.4 ), and $B$ the buoyancy flux $\left(\mathrm{m}^{2} \mathrm{~s}^{-3}\right)$, defined such that $B>0$ if stabilizing the 


(a)

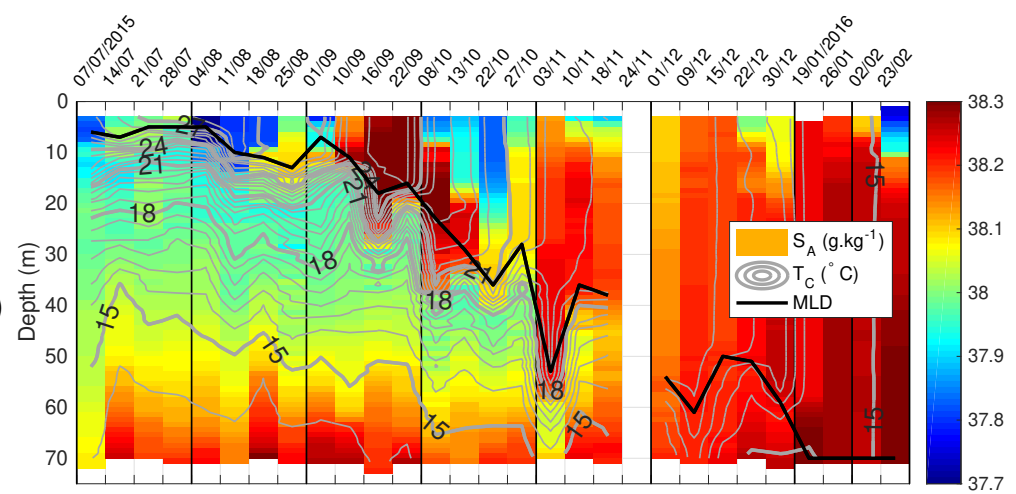

(b)

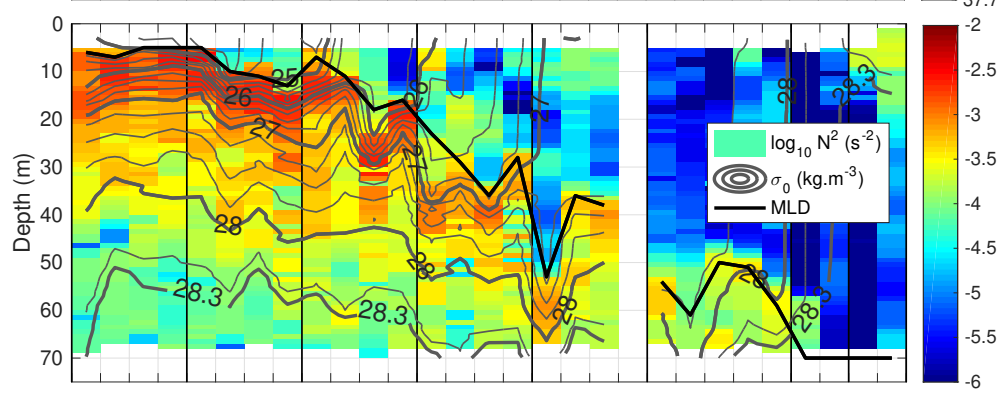

(c)

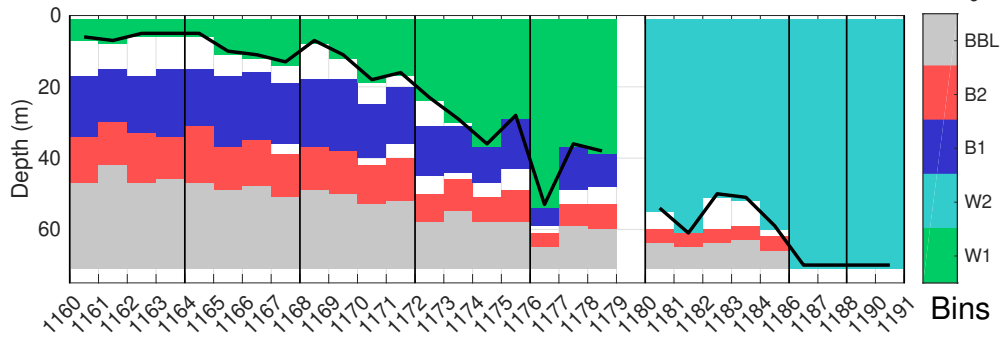

Figure 2: CTD SBE-911+ profiles. (a) Absolute Salinity $S_{A}\left(\mathrm{~g} \mathrm{~kg}^{-1}\right)$ with contours of Conservative temperature $T_{C}\left({ }^{\circ} \mathrm{C}\right)$. (b) Brunt-Väisälä frequency $N^{2}\left(\mathrm{~s}^{-2}\right)$ and contours of potential density $\sigma_{0}$, plotted from 24 to $27 \mathrm{~kg} \mathrm{~m}^{-3}$ every $0.25 \mathrm{~kg} \mathrm{~m}^{-3}$, with the 28.3 $\mathrm{kg} \mathrm{m}^{-3}$ isopycnal emphasized in thick black near the bottom. (c) Vertical and temporal bins used thereafter for the statistical characterization by periods and layers : surface to MLD during the summer to autumn period $W 1$ (green), surface to MLD during the winter period $W 2$ (cyan), the vertical layer of the shear maxima of the first baroclinic mode $B 1$ (blue) and second baroclinic mode $B 2$ (red), and the bottom boundary layer BBL (gray). (All) $M L D_{\theta_{0}}^{0.4^{\circ} \mathrm{C}}$ (thick black line). X-axis indicates the sequence of MC-CTD profiles references, and sampling dates are given on the panel top.

short episodes of negatively buoyant days (Fig. 3.a, gray line). In contrast, after midSeptember $B$ remained negative (or close to zero). Consequently, from the beginning of the observed period, the cumulative buoyancy flux increases and reaches a maximum level around mid-September and then constantly decreases from mid-October to reach a minimum at the end of the record (Fig. 3.a, gray dashed line). The contribution of heat $\left(B_{T}\right)$ and freshwater $\left(B_{S}\right)$ fluxes to daily buoyancy fluxes clearly show that $B_{T}$ dominates, being larger than $B_{S}$ by one order of magnitude except during rain events (Fig. 3.a and Fig. 3.b, blue lines). Precipitation rates shows intermittent events with values larger than $20 \mathrm{~mm} \mathrm{~d}^{-1}$, with a maximum of about $70 \mathrm{~mm} \mathrm{~d}^{-1}$ in early October, followed by intermittent rainy events during the rest of the period. During those events, (positive) $B_{S}$ became comparable to $B_{T}$ (Fig. 3.a, solid pink blue and gray lines). Note that without measurements of the river runoffs contribution, there were not accounted 
(a)

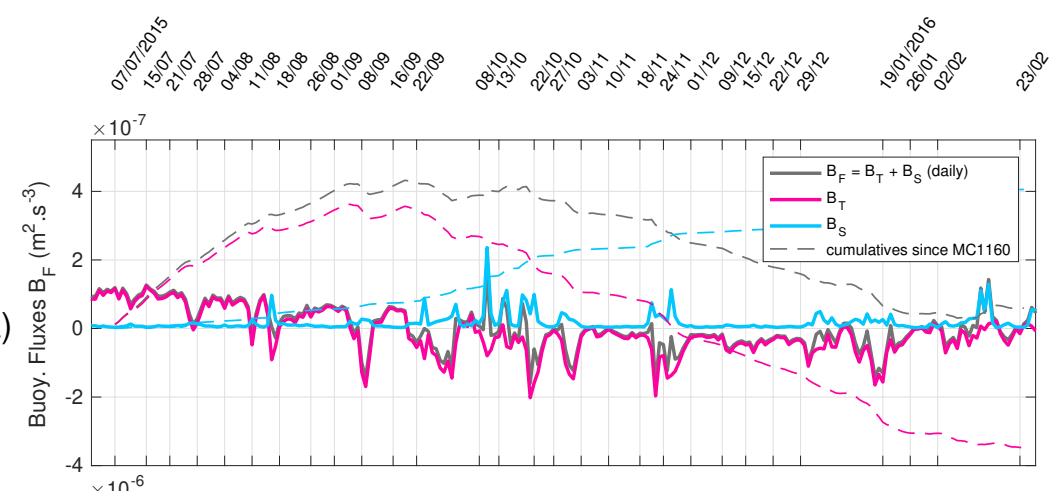

(b)

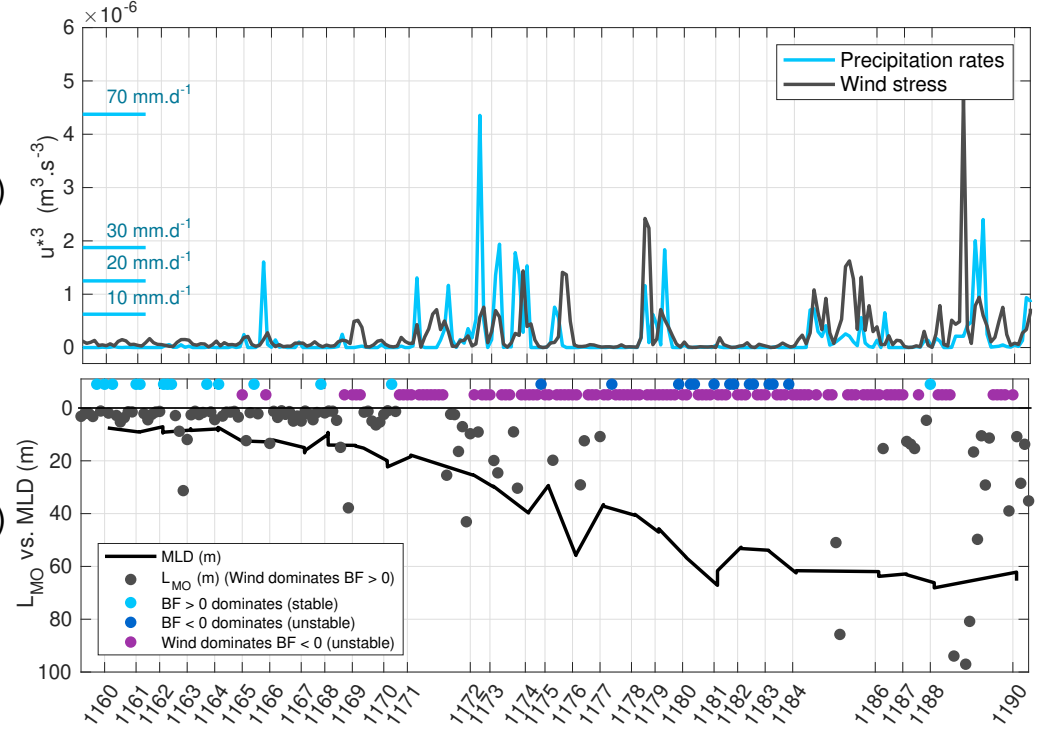
the Gulf of Naples is about $13 \mathrm{~m}^{3} \mathrm{~s}^{-1}$, while the Volturno river runoff into the Gulf of Gaeta is about $82 \mathrm{~m}^{3} \mathrm{~s}^{-1}$ (Albanese et al. [2012])).

Figure 3: (a) Daily averaged buoyancy fluxes $B\left(\mathrm{~m}^{2} \mathrm{~s}^{-3}\right)$. Gray line indicates the sum of heat and freshwater contributions $B_{T}$ (solid pink) and $B_{S}$ (solid blue). The associated dashed lines indicate the cumulative values from the 7th of July 2015 (scaled down by a factor 10 for graphical purposes). (b) Daily averaged precipitation rates $P\left(\mathrm{~mm} \mathrm{~d}^{-1}\right.$ in blue) and wind stress $u_{*}^{3}\left(\mathrm{~m}^{3} \mathrm{~s}^{-3}\right.$ in gray). (c) MLD (solid black) and Monin-Obhukov length scale $L_{M O}$ ( $\mathrm{m}$ in gray dots) during stable buoyancy fluxes. On the horizontal line near surface, dots indicate the occurences of the other regimes (stable in light blue, unstable dominated by negative fluxes in dark blue, and unstable fluxes dominated by wind stress in purple). X-axis indicates the MC-CTD casts references. Sampling dates are given on the panel top.

for despite they are likely of importance over this coastal area (the Sarno river runoff into 

(a)

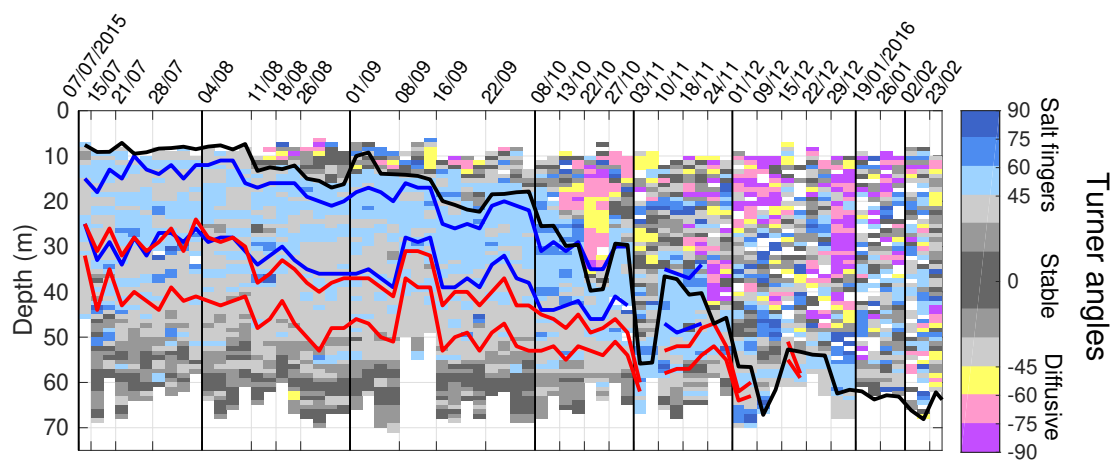

(b)

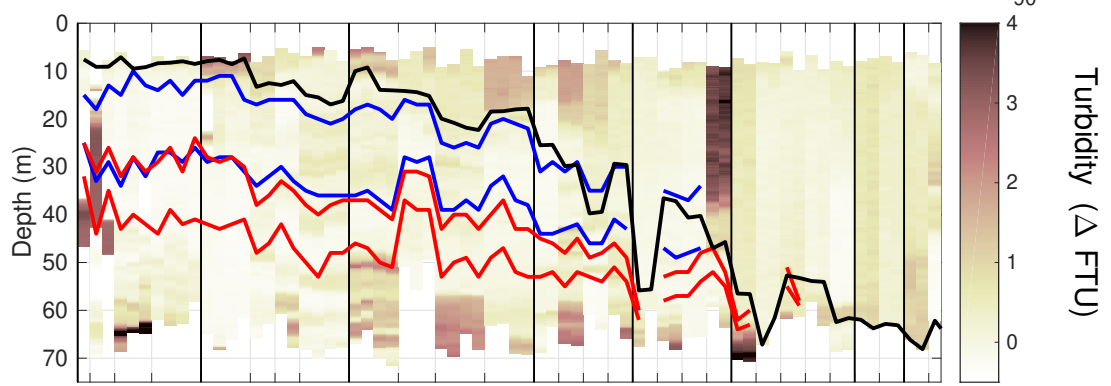

(c)

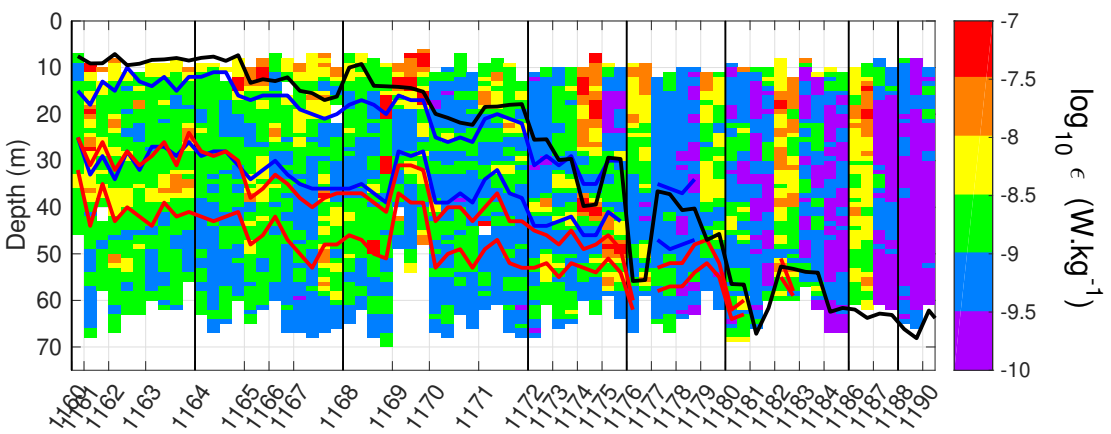

Figure 4: VMP-250 profiles, plotted sequentially ( $\mathrm{x}$-axis does not represent time). (a) Turner angles (angular ${ }^{\circ}$ ), (b) Turbidity $(\triangle F T U$ ) (offset from a reference value), and (c) Dissipation rate estimates $\left(\mathrm{W} \mathrm{kg}^{-1}\right)$. (All) $M L D_{\theta_{0}}^{0.4^{\circ} \mathrm{C}}$ (thick black), region of maximum energy of baroclinic mode 1 (between blue lines) and mode 2 (between red lines). The VMP profiles are plotted sequentially along the $\mathrm{x}$-axis, where the MC casts references are indicated (from one to four VMP profiles by cast). Sampling dates are given on the panel top.

ible (MC1175 on the supplementary Fig. S3.b, or MC1180 on Fig. S3.c). This provides evidence of the re-suspension of sediments in a non-tidal area, by energetic processes located between the MLD and the bottom boundary layer. Once a full vertical homogenization is achieved in January (the core of winter period), no additional turbid layers are observed. Looking at the subsurface, local turbid patches are present inside the ML from September to November, with structures occupying a large part of the water column (MC1179 on Fig. 4.b). This depicts the complexity of the winter mixing at the coastal area, underlying the possible important role of the runoffs discharging sediments at various point of the coast, and of the mesoscale and submesoscale features laterally advecting them. 


\subsection{Turbulent kinetic energy dissipation rate $\epsilon$}

The seasonal sequence of vertical profiles of dissipation rates of turbulent kinetic energy shows maximum values between $10^{-8}$ and $10^{-7} \mathrm{~W} \mathrm{~kg}^{-1}$ (Fig. 4.c), distributed through patches in various parts of the water column. For a given station, $\epsilon$ varies within a factor of five between the successive casts done typically within one hour (e.g., stations MC1163, MC1168, or MC1171). The summer period shows values of $10^{-8} \mathrm{~W} \mathrm{~kg}^{-1}$ at the depth-range of the MLD, around $10 \mathrm{~m}$. The most intense patches are from $5 \times 10^{-7}$ to $10^{-8} \mathrm{~W} \mathrm{~kg}^{-1}$ between 20 and $35 \mathrm{~m}$ in July (MC1160 to MC1163), then between 35 and $50 \mathrm{~m}$ in August and September (MC1164 to MC1171). They match the MLD depth in October (MC1174 and MC1175). Minimum values of $10^{-10} \mathrm{~W} \mathrm{~kg}^{-1}$ are measured, which are near the noise limit of the instrument. In winter, the dissipation rates are low throughout most of the water column (MC1184, MC1188, MC1190). The turbid patches identified previously are associated with local patches of $\epsilon$ from August to January, with values from $10^{-8}$ to $10^{-7} \mathrm{~W} \mathrm{~kg}^{-1}$ in surface from $10 \mathrm{~m}$ to around $20 \mathrm{~m}$ (MC1165, MC1171, $\mathrm{MC1174}$ ), and in the lower range of around $10^{-9}$ to $10^{-8} \mathrm{~W} \mathrm{~kg}^{-1}$, into the water column (MC1179, MC1186) or at the proximity of the bottom (MC1168, MC1173).

Profiles of $\epsilon$ are grouped by their mean and median values over the stratified period $W 1$ and winter period $W 2$ (Fig. 5). During $W 1$, the median profiles converge from $10^{-8}$ to $10^{-9} \mathrm{~W} \mathrm{~kg}^{-1}$ from 10 to $25 \mathrm{~m}$, and then remains around $10^{-9} \mathrm{~W} \mathrm{~kg}^{-1}$ down to the bottom, punctuated by local intense values $>10^{-7} \mathrm{~W} \mathrm{~kg}^{-1}$. Layers below the ML show intermittent local maximum values reaching $10^{-8} \mathrm{~W} \mathrm{~kg}^{-1}$, located in the vertical between region of the two first baroclinic modes maximum. The winter period $W 2$ shows a tendency of $\langle\epsilon\rangle$ values to be centered around $10^{-10}$ and $5 \times 10^{-8} \mathrm{~W} \mathrm{~kg}^{-1}$ (Fig. 5.b). Peaks are observed at various depths in the water-column, marking both spatial and temporal intermittency. They are more pronounced in the stratified layers, which may underline that intermittency is stronger in these locations. It should be noted that our observations were made when weather conditions were favourable for a safe deployment of the VMP-250, sometimes after energetic storms but certainly never during storms. Therefore, the most intense turbulent events are likely missed.

\subsection{Statistical description of $\epsilon$ and $N^{2}$}

To characterize the distributions of $\epsilon$, we applied the same framework as Lozovatsky et al. [2017]. We present in Fig. 6 the empirical probability density function (pdf) of $\epsilon$ and $N^{2}$ on the two forcing periods W1 and W2, and differentiate the surface from the internal and bottom layers B1, B2 and BBL (see Fig. 2.c).

3.6.0.1 Pdf of $\epsilon$ and $N^{2}$ The pdf for the surface bins (Fig. 6.a) shows values around $4 \times 10^{-10} \mathrm{~W} \mathrm{~kg}^{-1}$ for $\mathrm{W} 1$, and $2 \times 10^{-10} \mathrm{~W} \mathrm{~kg}^{-1}$ for $\mathrm{W} 2$, the latter being dominated by stronger winds and negative buoyancy fluxes. Both distribution are well fitted by a Burr type XII, and differ from log-normality. Regarding the stratification (Fig. 6.b), the summer to fall period shows a distribution centered on $5 \times 10^{-5} \mathrm{~s}^{-2}$ (W1 in green), while winter is characterized by a distribution centered on $3 \times 10^{-5} \mathrm{~s}^{-2}$ (W2 in cyan). Below the mixed layers (Fig. 6.c), the pdf of $\epsilon$ shows a dominant peak centered on $5 \times 10^{-10} \mathrm{~W} \mathrm{~kg}^{-1}$ for B1, and on $9 \times 10^{-10} \mathrm{~W} \mathrm{~kg}^{-1}$ for B2. The distribution within the BBL (Fig. 6.e) is narrower compared to B1 and B2, and shows a dominant peak centered on $7 \times 10^{-10} \mathrm{~W} \mathrm{~kg}^{-1}$. The observations are better described by the Burr type XII distribution than the log-normal, even if the deviation from log-normality is not so pronounced than for the distributions of the surface bins W1 and W2. Regarding the $N^{2}$ below the ML (Fig. 6.d), the pdf in B1 is centered around $4 \times 10^{-4} \mathrm{~s}^{-2}$ and close to log-normality. The distribution in B2 is more variable, with values spread in the range $2 \times 10^{-5}$ to $3 \times 10^{-4} \mathrm{~s}^{-2}$, making difficult to distinguish which distribution fits better. Similarly, in the BBL (Fig. 6.f) values are spread in a wide range $\left(3 \times 10^{-5}\right.$ to $2 \times 10^{-4}$ 
(a)

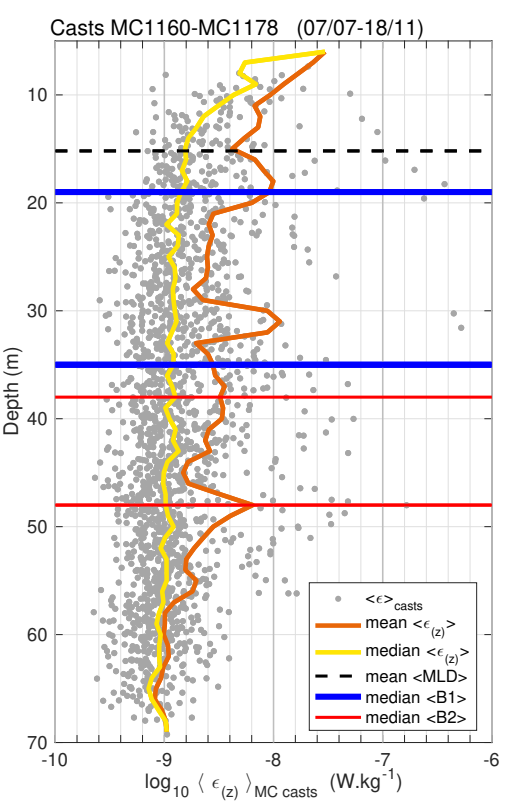

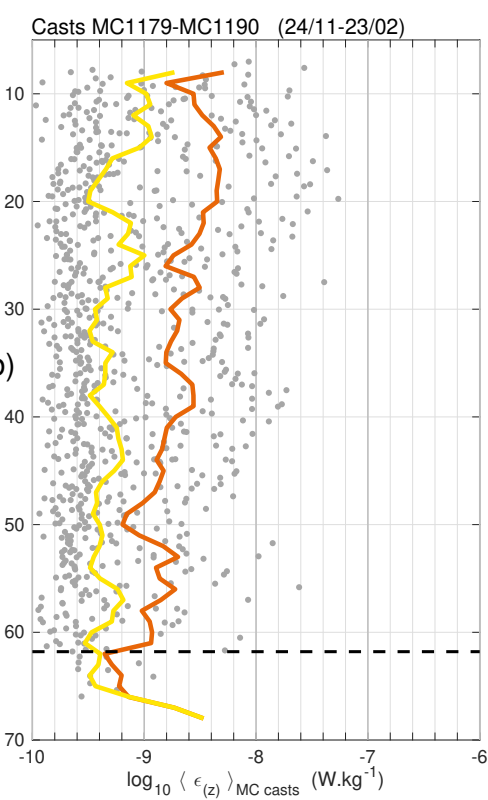

Casts MC1179-MC1190 (24/11-23/02)

(b)

Figure 5: Mean (orange) and median (yellow) profiles of $\epsilon\left(\mathrm{W} \mathrm{kg}^{-1}\right)$ over the (a) summerfall period W1 and (b) winter period W2. Gray background points are individual $\epsilon$ estimates. Horizontal dashed lines indicates the median depths of the MLD (black) and the upper and lower depths of B1 (blue) and B2 (red) during the stratified period $W 1$. Burr and log-normal distributions. Details of statistics are given in Tab. 1.a,b. 
(a)

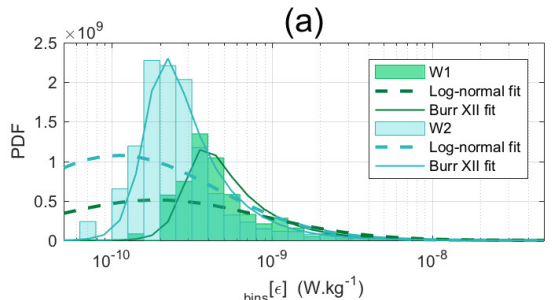

(c)

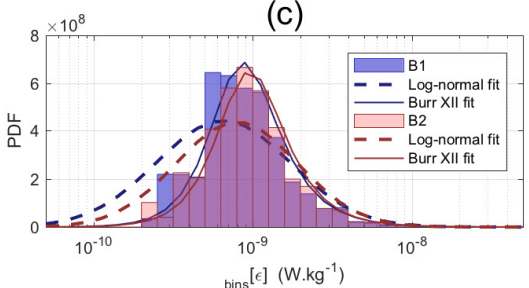

(e)

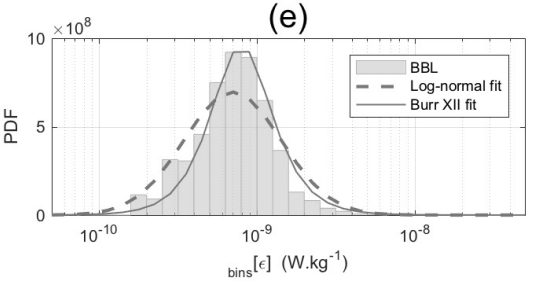

(b)

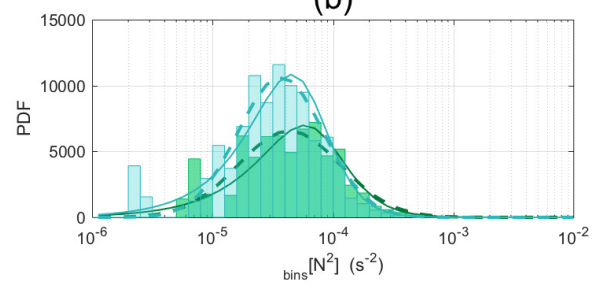

(d)

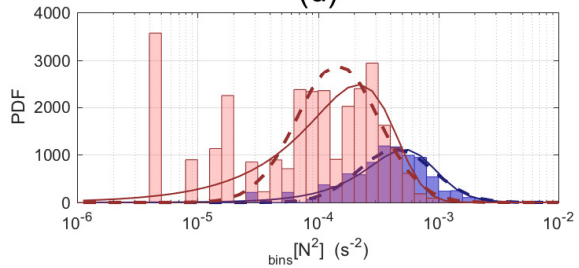

(f)

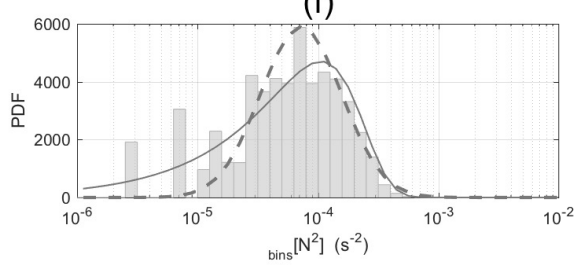

Figure 6: PDFs of $\epsilon\left(\mathrm{W} \mathrm{kg}^{-1}\right)$ (left), and $N^{2}\left(\mathrm{~s}^{-2}\right)$ (right), through temporal bins W1 and W2 (a,b), vertical layers B1 and B2 (c,d), and near the bottom BBL (e,f). Fits of log-normal and Burr type XII distribution are indicated with the dashed and plain black lines, respectively. Bins are shown on Fig. 2.c, and detailed statistics are given in Tab. 1. 
Table 1: Statistics of $\epsilon(\mathrm{a})$ and $N^{2}$ (b). For both quantities are given general statistics by bins, and parameters for the fits of log-normal and Burr Type XII distributions, with their confidence intervals (c.i.). (c) Parameters of the quadratic fit $K=a S^{2}+b$ of the $K=f(S)$.

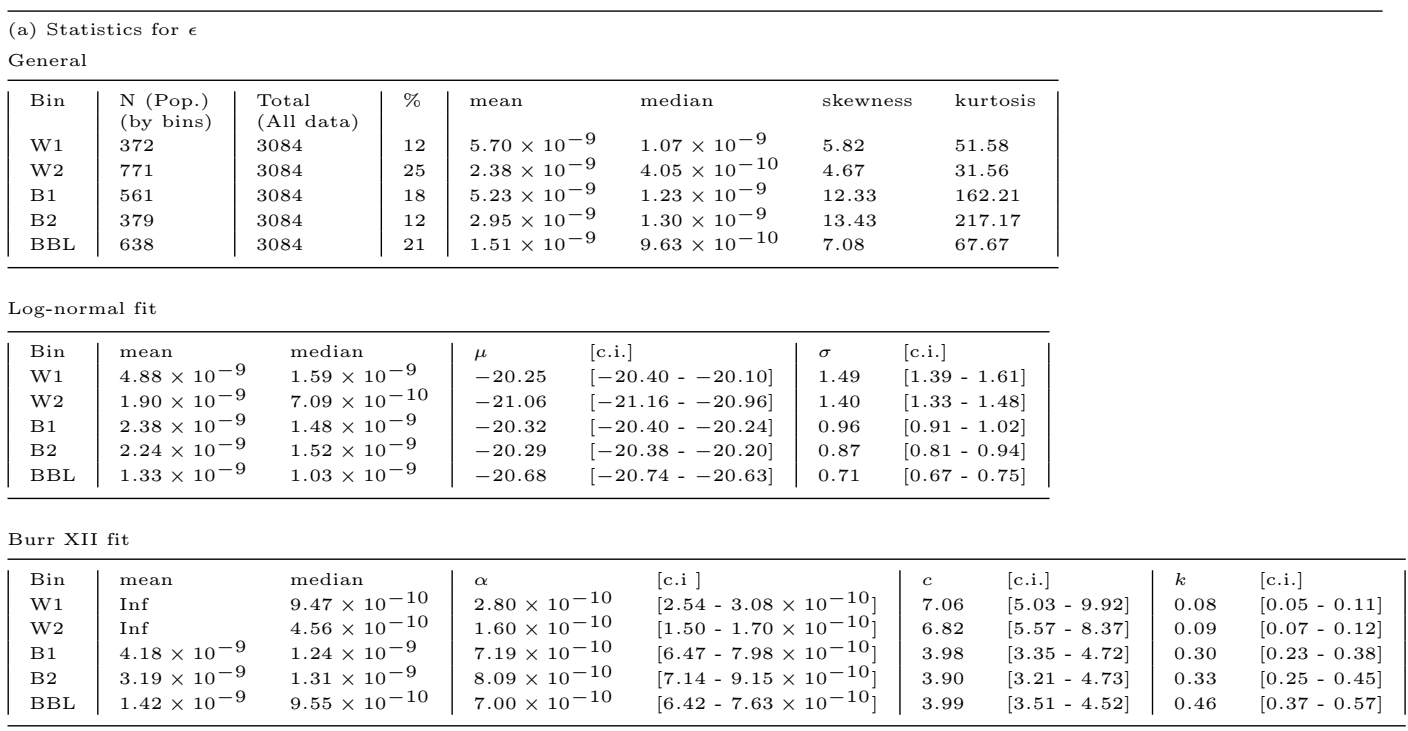

(b) Statistics for $N^{2}$

General

\begin{tabular}{|l|l|l|l|llll|}
\hline Bin & $\begin{array}{l}\text { N (Pop.) } \\
\text { (by bins) }\end{array}$ & $\begin{array}{l}\text { Total } \\
\text { (All data) }\end{array}$ & $\%$ & mean & median & skewness & kurtosis \\
W1 & 552 & 3863 & 14 & $1.71 \times 10^{-4}$ & $9.66 \times 10^{-5}$ & 4.27 & 24.76 \\
W2 & 990 & 3863 & 26 & $9.07 \times 10^{-5}$ & $6.35 \times 10^{-5}$ & 5.32 & 58.95 \\
B1 & 733 & 3863 & 19 & $8.27 \times 10^{-4}$ & $6.40 \times 10^{-4}$ & 1.65 & 5.85 \\
B2 & 544 & 3863 & 14 & $3.04 \times 10^{-4}$ & $2.74 \times 10^{-4}$ & 2.16 & 13.35 \\
BBL & 803 & 3863 & 21 & $1.49 \times 10^{-4}$ & $1.30 \times 10^{-4}$ & 1.01 & 4.24 \\
\hline
\end{tabular}

Log-normal fit

\begin{tabular}{|l|ll|ll|ll|}
\hline Bin & mean & median & $\mu$ & {$[$ c.i. $]$} & $\sigma$ & {$[$ c.i. $]$} \\
W1 & $1.61 \times 10^{-4}$ & $1.00 \times 10^{-4}$ & -9.20 & {$[-9.28--9.12]$} & 0.97 & {$[0.92-1.03]$} \\
W2 & $8.96 \times 10^{-5}$ & $6.41 \times 10^{-5}$ & -9.65 & {$[-9.70--9.60]$} & 0.81 & {$[0.78-0.85]$} \\
B1 & $8.34 \times 10^{-4}$ & $6.49 \times 10^{-4}$ & -7.33 & {$[-7.39--7.28]$} & 0.70 & {$[0.67-0.74]$} \\
B2 & $3.25 \times 10^{-4}$ & $2.39 \times 10^{-4}$ & -8.33 & {$[-8.40--8.27]$} & 0.78 & {$[0.73-0.83]$} \\
BBL & $1.59 \times 10^{-4}$ & $1.17 \times 10^{-4}$ & -9.04 & {$[-9.09--8.99]$} & 0.77 & {$[0.74-0.81]$} \\
\hline
\end{tabular}

Burr XII fit

\begin{tabular}{|l|ll|ll|ll|ll|}
\hline Bin & mean & median & $\alpha$ & {$[$ c.i. $]$} & {$[$ c.i. $]$} & $k$ & {$[$ c.i. $]$} \\
W1 & $1.95 \times 10^{-4}$ & $9.52 \times 10^{-5}$ & $7.52 \times 10^{-5}$ & {$\left[6.15-9.19 \times 10^{-5}\right]$} & 2.13 & {$[1.86-2.44]$} & 0.71 & {$[0.54-0.92]$} \\
W2 & $9.40 \times 10^{-5}$ & $6.33 \times 10^{-5}$ & $6.02 \times 10^{-5}$ & {$\left[5.09-7.12 \times 10^{-5}\right]$} & 2.24 & {$[2.03-2.48]$} & 0.92 & {$[0.72-1.17]$} \\
B1 & $8.49 \times 10^{-4}$ & $6.53 \times 10^{-4}$ & $6.89 \times 10^{-4}$ & {$\left[5.56-8.53 \times 10^{-4}\right]$} & 2.41 & {$[2.12-2.73]$} & 1.09 & {$[0.79-1.52]$} \\
B2 & $3.03 \times 10^{-4}$ & $2.65 \times 10^{-4}$ & $6.91 \times 10^{-4}$ & {$\left[4.50-11.0 \times 10^{-4}\right]$} & 1.87 & {$[1.69-2.06]$} & 4.50 & {$[2.46-8.20]$} \\
BBL & $1.49 \times 10^{-4}$ & $1.32 \times 10^{-4}$ & $9.05 \times 10^{-4}$ & {$\left[2.08-39.1 \times 10^{-4}\right]$} & 1.69 & {$[1.55-1.84]$} & 18.24 & {$[2.04-163.08]$} \\
\hline
\end{tabular}

(c) Quadratic fit parameters

\begin{tabular}{|lll|}
\hline & $\begin{array}{l}K_{\epsilon}=f\left(S_{\epsilon}\right) \\
K=a S^{2}+b\end{array}$ & $\begin{array}{l}K N^{2}=f\left(S_{N^{2}}\right) \\
K=a S^{2}+b\end{array}$ \\
\hline Coeff. (with 95\% conf. bounds) & $1.08(0.851 .31)$ & $1.82(0.892 .75)$ \\
a & $10.9(-13.735 .6)$ & $1.30(-12.9515 .56)$ \\
b & & \\
Goodness of fit & 322.5 & 144.8 \\
SSE & 0.98 & 0.92 \\
R-square & 0.98 & 0.90 \\
Adjusted R-square & 10.3 & 6.94 \\
RMSE & & \\
\hline
\end{tabular}


3.6.0.2 Relationships between observations To complete the statistical characterization, we computed the skewness $S$ and kurtosis $K$, which are indicators of the symmetry and the intermittency, respectively, of the observed variable (Fig. 7.a). The relationship between kurtosis $K$ and skewness $S$ of the different measured parameters was assessed by fitting a quadratic function $K=a S^{2}+b$ for $\epsilon$ and $N^{2}$ (fit parameters can be found in Tab. 1.c). Additionally, theoretical curves for the log-normal and Gamma distributions are presented to allow for a comparison. Our statistics reproduce the same behaviour as in Lozovatsky et al. [2017]. The quadratic relationship fits well the dissipation rate observations (Fig. 7.a, squares over the black line) whose distribution is closer to the Gamma than to the log-normal distribution. Regarding the absolute values of the high order statistics, the stratified bins B1 and B2 are less symmetric and intermittent than for the surface bins W1 and W2, with the bottom bin BBL standing in between while being closer to the latter. Median values of $\epsilon$ (Fig. 7.b) indicate a partition between stratified and mixed layers, decreasing from $11 \times 10^{-10} \mathrm{~W} \mathrm{~kg}^{-1}$ in the transitional period summer-to-fall ( $W 1$ in green) to $4 \times 10^{-10} \mathrm{~W} \mathrm{~kg}^{-1}$ in winter ( $W 2$ in cyan). The strongest median values are around $13 \times 10^{-10} \mathrm{~W} \mathrm{~kg}^{-1}$ and concern the stratified bins ( $B 1$ in blue, and $B 2$ in red). In term of distribution, $N^{2}$ (Fig. 7.a) appear to be close to the log-normal distribution for the stratified bins (B1 in blue triangle, B2 in red, and $\mathrm{BBL}$ in gray), and differ in the mixed layers (W1 in green triangle and W2 in cyan). Its kurtosis (and skewness, not shown) clearly decreases in function of the intensity of the stratification (Fig. 7.c).

(a)

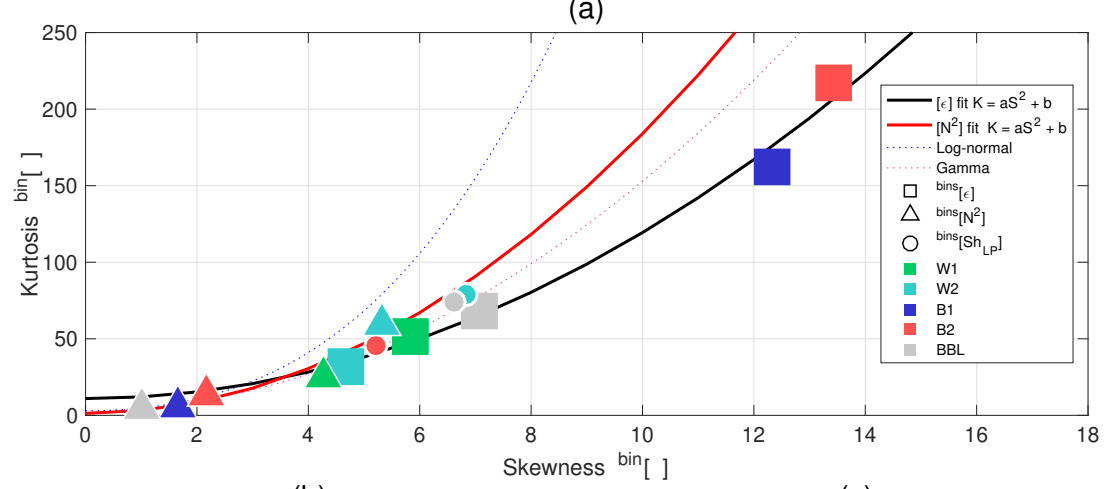

(b)

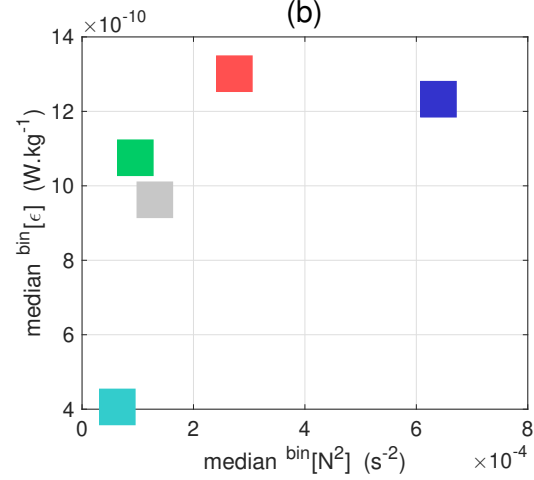

(c)

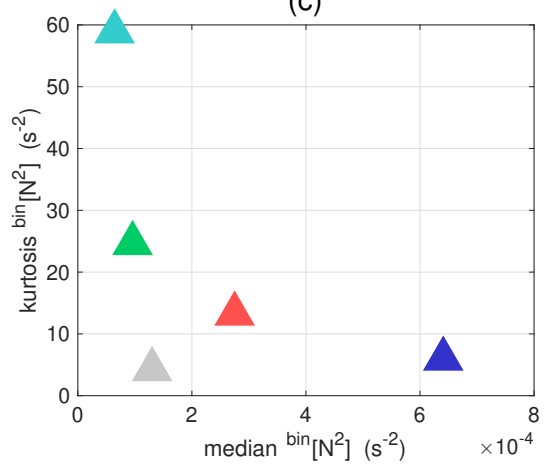

Figure 7: (a) Skewness $(S)$ and kurtosis $(K)$ of $\epsilon$ (squares), $N^{2}$ (triangles), and $S h_{L P}$ (dots), for the different temporal and vertical groups of data (colors refer to the bins on Fig. 2.c). A discussion dedicated to $S h_{L P}$ is given in the Appendix. Black and red plain lines indicate quadratic fits $K=a S^{2}+b$ as proposed by Lozovatsky et al. [2017] and applied to $\epsilon$ and $N^{2}$. Statistics of the parameters can be consulted in Tab. 1. Blue and red dashed lines indicates theoretical curves for log-normal and Gamma distributions. (b) Median of $\epsilon\left(\mathrm{W} \mathrm{kg}^{-1}\right)$ and (c) kurtosis of $N^{2}\left(\mathrm{~s}^{-2}\right)$, in function of the median of $N^{2}\left(\mathrm{~s}^{-2}\right)$. 


\section{Discussion}

We used CTD and microstructure observations to depict the time evolution of the water column in the Gulf of Naples, a mid-latitude non-tidal coastal site. This data set showed a deepening of the ML starting in late summer, marked by intermittent high dissipation rates below the MLD. Closer to the surface, we observed short periods of enhanced turbulence that may contribute to the deepening of the ML. We review here some mechanisms potentially relevant to explain our coastal observations, synthesised schematically on Fig. 8.

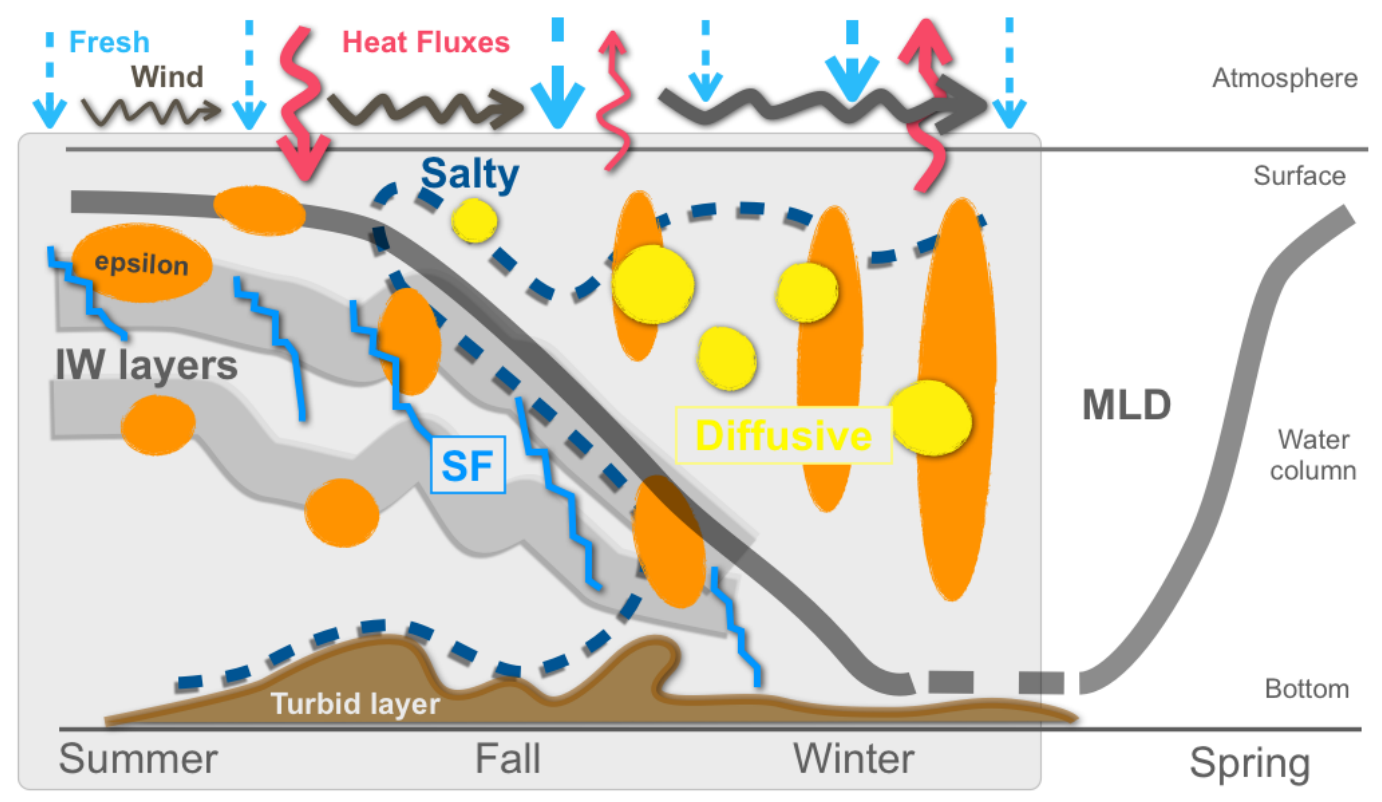

Figure 8: Schematic representation of the relevant processes identified in this study for seasonal destratification cycle, at the LTER-MC site in the Gulf Of Naples, by $75 \mathrm{~m}$ deep, from July 2015 to February 2016. Freshwater (blue dashed arrows), wind stress (gray arrows) and buoyancy fluxes (red arrows) are represented at the surface. The salty tongue observed in the hydrology is depicted in dashed dark blue, while the turbid bottom layer is shown in brown. The MLD is schematized in thick gray. The two regions occupied by the first two baroclinic modes of internal waves (IW) are indicated by the shaded layers below the MLD. Schematic patches showing intensified turbulent kinetic energy dissipation rates are plotted in orange. Salt fingering (SF) and diffusive convection regimes are schematized by the blue stairs and the yellow circles, respectively.

The shallow waters of the GoN are strongly influenced by the atmospheric forcings. Positive buoyancy fluxes in summer (Fig. 8, pink arrow pointing down) maintain a strong stratification that light summer winds (Fig. 8, black curly lines) can hardly break. Storms started at the end of summer with dominating enhanced wind episodes and the first negative buoyancy fluxes (Fig. 8, pink arrow pointing up), both contributing to a deepening of the ML. Fall and winter periods were marked by increasingly negative buoyancy fluxes and few intermittent episodes of strong wind.

Regarding the water column T-S properties, the close-by Sarno River, located in the northeast corner of the GoN (Fig. 1), is a potential source of freshwater anomalies propagating along the east side of the Gulf. This river could thus be the main source of the low salinity content of surface waters observed from July to October (Fig. 8, vertical dashed blue arrows) even if the study of Cianelli et al. [2012] showed that this in- 


(a)
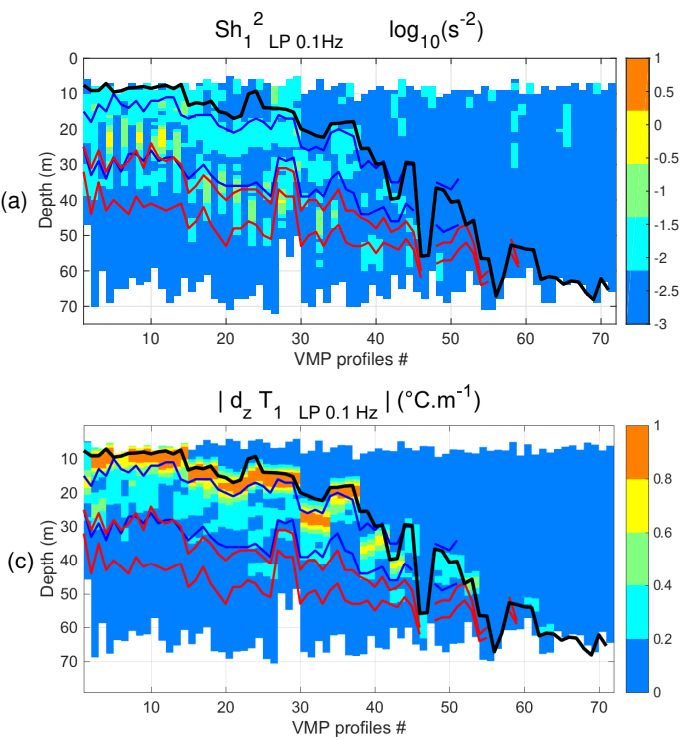
that are worth presenting.

$S h_{L P}^{1,2}=\left\langle(d u / d z)^{2}\right\rangle_{L P}^{0.1 H z},\left\langle(d v / d z)^{2}\right\rangle_{L P}^{0.1 H z}$. content).

\section{Appendix A Low frequency signals in the microstructure shears data}

This section is motivated by the repeated observation of a low-frequency signal in our microstructure shear data, while the instrument's fall speed remained constant. This signal was observed within stratified layers, at the MLD and below the MLD, depicting vertical patterns during our survey (Fig. A1). We propose here a first attempt to separate parts of the signal that may be due to strong thermal gradients (pyro-effect, as discussed after), and other ones possibly due to other noise sources, or real energetic motions. The shear probes are sensitive to velocity fluctuations at frequencies greater than $0.1 \mathrm{~Hz}$, but the signals are often high-pass filtered at higher frequencies $(\sim 0.4 \mathrm{~Hz})$ before computing the spectra and the dissipation rate. Here we intended to carefully use the low frequency part of shear signals since no other sources of velocity shear were available. However, it is most likely that the low-frequency response in the micro-structure shear data is due to passing through strong thermal gradients, an effect known as the pyro-electric effect, which cannot be interpreted as a physical shear signal (see below). Despite this, an analysis of the low frequency signal still shows some interesting patterns

For the analysis, we defined low-passed shear energy estimates $S h_{L P}^{1,2}$ from shear 1 and 2, calculated by low-pass filtering the despiked shears at $0.1 \mathrm{~Hz}$, as

In our dataset, structures linked to this low-frequency signal showed vertical scales of around $3 \mathrm{~m}$. We show on Fig. A1 time filtered quantities at $0.1 \mathrm{~Hz}$, that are equivalent to a spatial filtering over these length scales. We note that spatial filtering has the advantage to avoid numerical negative values (e.g. if used to estimate a proper energy

\section{(b)}
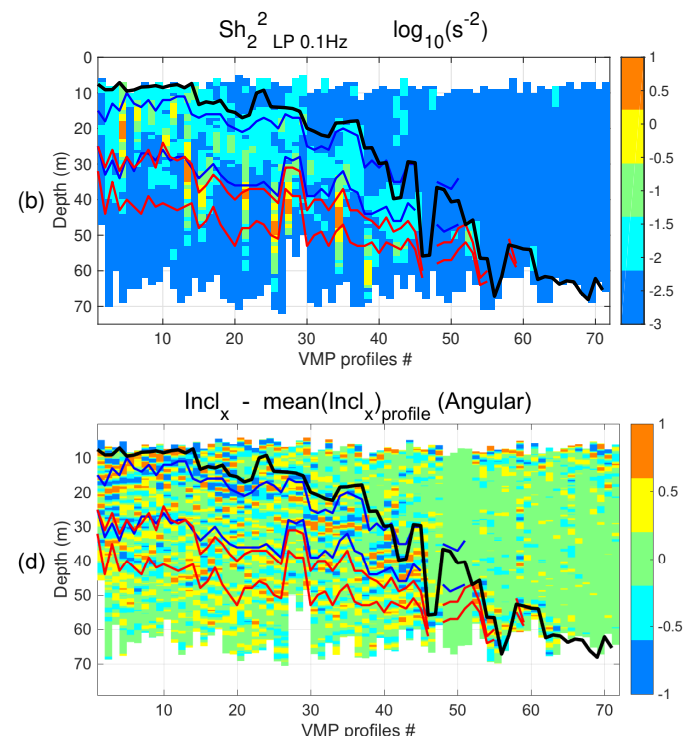

Figure A1: Square value of the microstructure shears 1 (a) and 2 (b) (i.e. $d u / d z$ and $d v / d z$, respectively) low pass filtered at $0.1 \mathrm{~Hz}\left(\mathrm{~s}^{-2}\right)$. We plotted the absolute values due to numerical negative values created by the filtering after the square operator. Profiles examples are shown on supplementary Fig. S3. (c) Microstructure gradients $d T / d z\left({ }^{\circ} \mathrm{m}^{-1}\right)$ low-passed filtered at $0.1 \mathrm{~Hz}$, and plotted in absolute value, showing subsurface layers concerned by strong vertical thermal gradients. These are mainly located between the base of the MLD and the upper limit of the envelope of the baroclinic mode B1. (d) Anomaly to the mean value of the roll inclination of the VMP-250 (angular ${ }^{\circ}$ relative to the $\mathrm{x}$-axis). 


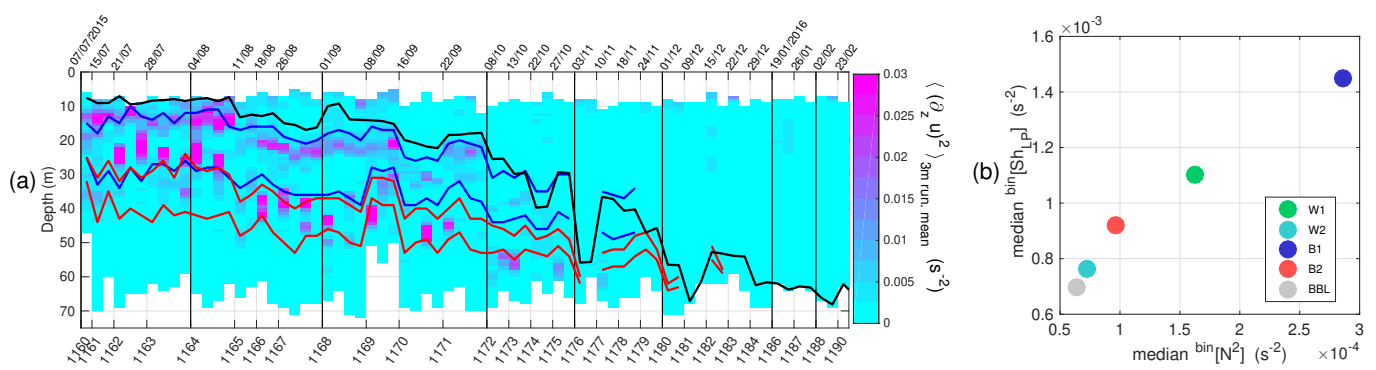

Figure A2: (a) Low pass shear energy $S h_{L P}$ i.e. $\left\langle\left(\partial_{z} u\right)^{2}\right\rangle_{L P}^{3 m}\left(\mathrm{~s}^{-2}\right), M L D_{\theta_{0}}^{0.4^{\circ} C}$ (thick black line), region of maximum energy of baroclinic mode 1 (between blue lines) and mode 2 (between red lines). The VMP profiles are plotted sequentially along the $\mathrm{x}$-axis, where the MC casts references are indicated (from one to four VMP profiles by cast). Sampling dates are given on the panel top. (b) Median of $S h_{L P}\left(\mathrm{~s}^{-2}\right)$ in function of the median of $N^{2}\left(\mathrm{~s}^{-2}\right)$.

with B2 and it is clearly visible during August and September while having less intense imprint in July and October. Elsewhere, the low pass shear is weak whenever the stratification is weak (e.g., ML and BBL). Pdfs are shown in the supplementary information (Fig. S4). Although $S h_{L P}$ and $\epsilon$ are estimated over totally independent wavenumber ranges, their kurtosis-skewness relationship follows the same quadratic fit out of the log-normality (Fig. 7.a, dots and squares). In addition, $S h_{L P}$ shows a remarkable linearity as a function of the stratification intensity (Fig. A2.b), while $\epsilon$ does not show such a linear relationship with the stratification (Fig. 7.a). The $S h_{L P}$ estimate presented here is not conventional and its interpretation would require a thoughtful validation via a comparison with Acoustic Doppler Current Profiler (ADCP) observations. While to be considered with great caution, we documented in Fig. S5 the distribution of $\epsilon$ in function of $N^{2}$ and $S h_{L P}$ as proxy of the shear (Gill [1982], Monin \& Yaglom [2007]). Interestingly, it shows higher $\epsilon$ values in correspondence with a weaker stratification and larger shear values. The dependence from the stratification intensity is lost in the ML (W1 and W2), while a modulation by $N$ is suggested in the stratified layers B1, B2 and BBL, following the observations of Vladoiu et al. [2018] that tested a wave-wave parameterization for $\epsilon$ based on MacKinnon \& Gregg [2003] .

\section{Acknowledgments}

Data sets for this research are available under netcdf format on https://github.com/ nerea-observatory/ltermc-microstructure. We would like to thank the LTER-MC team that includes, besides the main authors: D. d'Alelio, C. Balestra, M. Cannavacciuolo, R. Casotti, I. Di Capua, F. Margiotta, M. G. Mazzocchi, M. Montresor, A. Passarelli, I. Percopo, M. Ribera d'Alcalà, M. Saggiomo, V. Saggiomo, D. Sarno, F. Tramontano, G. Zazo, A. Zingone, all based at Stazione Zoologica Anton Dohrn of Naples. Special thanks must be given to the commandants and crews of the R/V Vettoria. The research program LTER-MC is supported by the Stazione Zoologica Anton Dohrn.

\section{References}

Albanese, S., Iavazzo, P., Adamo, P., Lima, A., \& De Vivo, B. (2012, 09). Assessment of the environmental conditions of the sarno river basin (south italy): A stream sediment approach. Environmental Geochemistry and Health, 35. doi: 10.1007/s10653-012-9483-x

Baldi, M., Dalu, G., Maracchi, G., Pasqui, M., \& Cesarone, F. $\quad(2006,09) . \quad$ Heat 
waves in the mediterranean: A local feature or a larger-scale effect? International Journal of Climatology, 26, 1477-1487. doi: 10.1002/joc.1389

Barton, A., Ward, B., Williams, R., \& Follows, M. (2014, 04). The impact of finescale turbulence on phytoplankton community structure. Limnology and Oceanography: Fluids and Environments, 4. doi: 10.1215/21573689-2651533

Benway, H. M., Lorenzoni, L., White, A. E., Fiedler, B., Levine, N. M., Nicholson, D. P., ... Letelier, R. M. (2019). Ocean time series observations of changing marine ecosystems: An era of integration, synthesis, and societal applications. Frontiers in Marine Science, 6, 393. doi: 10.3389/fmars.2019.00393

Brainerd, K. E., \& Gregg, M. C. (1995). Surface mixed and mixing layer depths. Deep-Sea Research I, 42, 1521-1543.

Brody, S. R., , \& Lozier, M. S. (2014). Changes in dominant mixing length scales as a driver of subpolar phytoplankton bloom initiation in the north atlantic. Geophysical Research Letter, 41 (9), 3197-3203.

Buckingham, C. E., Lucas, N. S., Belcher, S. E., Rippeth, T. P., Grant, A. L. M., , \& Lesommer, J. (2019). The contribution of surface and submesoscale processes to turbulence in the open ocean surfaceboundary layer. Journal of Advances in Modeling Earth Systems, 11, 4066-4099. doi: https://doi.org/10.1029/2019MS001801

(C3S), C. C. C. S. (2017). Era5: Fifth generation of ecmwf atmospheric reanalyses of the global climate. Copernicus Climate Change Service Climate Data Store $(C D S)$, date of access. doi: https://cds.climate.copernicus.eu/cdsapp\#!/home

Cianelli, D., D'Alelio, D., Uttieri, M., Sarno, D., Zingone, A., Zambianchi, E., \& Ribera d'Alcala, M. $\quad(2017,12)$. Disentangling physical and biological drivers of phytoplankton dynamics in a coastal system. Scientific Reports, $\%$ doi: 10.1038/s41598-017-15880-x

Cianelli, D., Uttieri, M., Buonocore, B., Falco, P., Zambardino, G., \& Zambianchi, E. (2012, 08). Dynamics of a very special mediterranean coastal area: the gulf of naples. Mediterranean Ecosystems: Dynamics, Management and Conservation, $129-150$

de Boyer Montégut, C., Madec, G., Fischer, A. S., Lazar, A., \& Iudicone, D. (2004, 01). Mixed layer depth over the global ocean: An examination of profile data and profile-based climatology. Journal of Geophysical Research, 109, C12003. doi: 10 $.1029 / 2004 J C 002378$

de Ruggiero, P., Ernesto, N., Iacono, R., Pierini, S., \& Spezie, G. (2018, 09). A baroclinic coastal trapped wave event in the gulf of naples (tyrrhenian sea). Ocean Dynamics. doi: 10.1007/s10236-018-1221-1

Durante, S., Schroeder, K., Mazzei, L., Pierini, S., Borghini, M., \& Sparnocchia, S. $(2019,01)$. Permanent thermohaline staircases in the tyrrhenian sea. Geophysical Research Letters. doi: 10.1029/2018GL081747

Ferrari, R., \& Wunsch, C. (2009). Ocean circulation kinetic energy: Reservoirs, sources, and sinks. Annual Review of Fluid Mechanics, 41, 253-282.

Garrett, C., Keeley, J., \& Greenberg, D. $\quad(1978,12)$. Tidal mixing versus thermal stratification in the bay of fundy and gulf of maine. Atmosphere-Ocean, 16, 403423. doi: $10.1080 / 07055900.1978 .9649046$

GEBCO, C. G. (2020). Gebco 2020 grid. Retrieved from https://www .gebco.net doi: $10.5285 /$ a29c5465-b138-234d-e053-6c86abc040b9

Gill, A. (1982, 01). Atmosphere-ocean dynamics. In (Vol. 30, p. 662).

Goodman, L., Levine, E. R., , \& Lueck, R. G. (2006). On measuring the terms of the turbulent kinetic energy budget from an auv. Journal of Atmospheric and Oceanic Technology, 23, 977-990.

Guancheng, l., Cheng, L., Zhu, J., Trenberth, K., Mann, M., \& Abraham, J. $\quad$ (2020, 09). Increasing ocean stratification over the past half-century. Nature Climate Change, 1-8. doi: 10.1038/s41558-020-00918-2

Hegerl, G. C., Black, E., Allan, R. P., Ingram, W. J., Polson, D., Trenberth, K. E., 
... Zhang, X. (2015). Challenges in quantifying changes in the global water cycle. Bulletin of the American Meteorological Society, 96(7), 1097-1115.

Iermano, I., Liguori, G., Iudicone, D., Buongiorno Nardelli, B., Colella, S., Zingone, A., ... Ribera d'Alcala, M. (2012). Dynamics of short-living filaments and their relationship with intense rainfall events and river flows. Progress in Oceanography, 106, 118-137. doi: 10.1016/j.pocean.2012.08.003

Inoue, R., Yamazaki, H., Wolk, F., Kono, T., \& Yoshida, J. (2007, 03). An estimation of buoyancy flux for a mixture of turbulence and double diffusion. Journal of Physical Oceanography, 37. doi: 10.1175/JPO2996.1

Johnston, T., \& Rudnick, D. (2009, 03). Observations of the transition layer. Journal of Physical Oceanography, 39. doi: 10.1175/2008JPO3824.1

Kelly, S. (2019, 09). Coastally generated near-inertial waves. Journal of Physical Oceanography, 49. doi: 10.1175/JPO-D-18-0148.1

Kiørboe, T., \& Mackenzie, B. (1995, 12). Turbulence-enhanced prey encounter rates in larval fish: Effects of spatial scale, larval behaviour and size. Journal of Plankton Research, 17, 2319-2331. doi: 10.1093/plankt/17.12.2319

Koseki, S., Mooney, P., Cabos Narvaez, W. D., Gaertner, m., de la Vara, A., \& Aleman, J. $\quad(2020,07)$. Modelling a tropical-like cyclone in the mediterranean sea under present and warmer climate. doi: $10.5194 /$ nhess-2020-187

Large, W., \& Pond, S. $\quad(1981,01)$ Open ocean momentum flux measurement in moderate to strong winds. Journal of Physical Oceanography, 11, 336-342.

Linden, P. $\quad(1976,10)$. The formation and destruction of fine-structure by doublediffusive processes. Deep Sea Research and Oceanographic Abstracts, 23, 895-908. doi: 10.1016/0011-7471(76)90820-2

Lozovatsky, I., H.J.S., F., J., P.-M., Liu, Z., Lee, J. H., \& Jinadasa, S. $\quad$ (2017, 08). Probability distribution of turbulent kinetic energy dissipation rate in ocean: Observations and approximations. Journal of Geophysical Research, 122. doi: $10.1002 / 2017 \mathrm{jc} 013076$

Lueck, R. (2016). Rsi technical note 028 : Calculating the rate of dissipation of turbulent kinetic energy. Rockland Scientific International Inc..

Lueck, R., Wolk, F., \& Yamazaki, H. $\quad(2002,02)$. Oceanic velocity microstructure measurements in the 20th century. Journal of Physical Oceanography, 58, 153174. doi: 10.1023/A:1015837020019

MacKinnon, J., \& Gregg, M. (2003, 07). Mixing on the late-summer new england shelf - solibores, shear, and stratification. Journal of Physical Oceanography, 33, 1476-1492. doi: 10.1175/1520-0485(2003)033〈1476:MOTLNE〉2.0.CO;2

Mackinnon, J. A., \& Gregg, M. C. (2005). Near-inertial waves on the new england shelf: The role of evolving stratification, turbulent dissipation, and bottom drag. Journal of Physical Oceanography, 35, 2408-2424.

Mann, K. H., \& Lazier, J. R. N. (1996). Dynamics of marine ecosystems.

Maurer, B., \& Linden, P. (2014, 08). Intrusion-generated waves in a linearly stratified fluid. Journal of Fluid Mechanics, 752, 282-295. doi: 10.1017/jfm.2014.316

McDougall, T., \& Barker, P. (2011). Getting started with teos-10 and the gibbs seawater (gsw) oceanographic toolbox. SCOR/IAPSO WG, 127, 1-28.

Monin, A., \& Yaglom, A. (2007). Statistical fluid mechanics, volume 1: Mechanics of turbulence.

Muralt, P. (2005). Pyroelectricity. In F. Bassani, G. L. Liedl, \& P. Wyder (Eds.), Encyclopedia of condensed matter physics (pp. 441-448). Oxford: Elsevier. doi: 10 .1016/B0-12-369401-9/00434-4

Nuttall, A. H. (1971). Spectral estimation by means of overlapped fast fourier transform processing of windowed data. NUSC Tech. Rep. No. 4169. doi: https://apps .dtic.mil/sti/pdfs/AD0739315.pdf 
Obukhov, A. (n.d.). Turbulentnost'v temperaturnojneodnorodnoj atmosfere ("turbulence in an atmosphere with a non-uniform temperature"). Tr. Inst. Teor. Geofiz. Akad. Nauk. SSSR., 1, 95-115.

Obukhov, A. (1971, 01). Turbulence in an atmosphere with non-uniform temperature. Boundary-Layer Meteorology, 2, 7-29. doi: 10.1007/BF00718085

Osborn, T. (1998, 01). Finestructure, microstructure, and thin layers. Oceanography, 11. doi: $10.5670 /$ oceanog. 1998.13

Passaro, S., Tamburrino, S., Vallefuoco, M., Gherardi, S., Sacchi, M., \& Guido, V. (2016, 06). High-resolution morpho-bathymetry of the gulf of naples, eastern tyrrhenian sea. Journal of Maps, 1-8. doi: 10.1080/17445647.2016.1191385

Pastor, F., Valiente, J. A., , \& Palau, J. L. (2018). Sea surface temperature in the mediterranean: Trends and spatial patterns (1982-2016). Pure and Applied Geophysics, 175, 4017-4029. doi: https://doi.org/10.1007/s00024-017-1739-z

Pearson, B., \& Fox-Kemper, B. $\quad$ (2018, 02). Log-normal turbulence dissipation in global ocean models. Physical Review Letters, 120. doi: 10.1103/PhysRevLett.120 .094501

Pingree, R., Holligan, P., Mardell, G., \& Head, R. (1976, 11). The influence of physical stability on spring, summer and autumn phytoplankton blooms in the celtic sea. Journal of the Marine Biological Association of the United Kingdom, 56 , 845-873. doi: 10.1017/S0025315400020919

Pinkel, R., Goldin, M., Smith, J., Sun, O., Aja, A., Bui, M., \& Hughen, T. $\quad$ (2011, 03). The wirewalker: A vertically profiling instrument carrier powered by ocean waves. Journal of Atmospheric and Oceanic Technology, 28, 426-435. doi: 10.1175/2010JTECHO805.1

Pisano, A., Marullo, S., Artale, V., Falcini, F., Yang, C., Leonelli, F., ... Buongiorno Nardelli, B. (2020, 01). New evidence of mediterranean climate change and variability from sea surface temperature observations. Remote Sensing, 12. doi: $10.3390 / \mathrm{rs} 12010132$

Polton, J., Smith, J., Mackinnon, J., \& Tejada-Martínez, A. $\quad(2008,07) . \quad$ Rapid generation of high-frequency internal waves beneath a wind and wave forced oceanic surface mixed layer. Geophysical Research Letters, 35. doi: 10.1029/ 2008GL033856

Prairie, J., Sutherland, K., Nickols, K., \& Kaltenberg, A. $\quad(2012,04) . \quad$ Biophysical interactions in the plankton: A cross-scale review. Limnology and Oceanography: Fluids and Environments, 2. doi: 10.1215/21573689-1964713

Ribera d'Alcala, M., Conversano, F., Corato, F., Licandro, P., Mangoni, O., Marino, D., ... Zingone, A. $\quad(2004,04)$. Seasonal patterns in plankton communities in pluriannual time series at a coastal mediterranean site (gulf of naples): An attempt to discern recurrences and trends. Scientia Marina, 68, 65-83.

Roemmich, D., Alford, M., Claustre, H., Johnson, K., King, B., Moum, J., ... Yasuda, I. $(2019,08)$. On the future of argo: A global, full-depth, multi-disciplinary array. Frontiers in Marine Science, 6. doi: 10.3389/fmars.2019.00439

Ruddick, B. $(1983,10)$. A practical indicator of the stability of the water column to double-diffusive activity. Deep Sea Research Part A. Oceanographic Research Papers, 30, 1105-1107. doi: 10.1016/0198-0149(83)90063-8

Ruddick, B., Anis, A., \& Thompson, K. $\quad(2000,11)$. Maximum likelihood spectral fitting: The batchelor spectrum. Journal of Atmospheric and Oceanic Technology, 17, 1541-1555. doi: 10.1175/1520-0426(2000)017〈1541:MLSFTB $\rangle 2.0 . C O ; 2$

Ruddick, B., \& Richards, K. (2003, 03). Oceanic thermohaline intrusions: Observations. Progress In Oceanography, 56, 499-527. doi: 10.1016/S0079-6611(03)00028 $-4$

Ruddick, B., \& Turner, J. (1979, 08). The vertical length scale of double-diffusive intrusions. Deep Sea Research Part A. Oceanographic Research Papers, 26, 903-913. doi: 10.1016/0198-0149(79)90104-3 
Schopflocher, T., \& Sullivan, P. (2005, 06). The relationship between skewness and kurtosis of a diffusing scalar. Boundary-Layer Meteorology, 115, 341-358. doi: 10 $.1007 / \mathrm{s} 10546-004-5642-7$

Shang, X., Qi, Y., Chen, G., Liang, C., Lueck, R., Prairie, B., \& Li, H. $\quad$ (2016, 10). An expendable microstructure profiler for deep ocean measurements. Journal of Atmospheric and Oceanic Technology, 34. doi: 10.1175/JTECH-D-16-0083.1

Skliris, N., Marsh, R., Josey, S. A., Good, S. A., Liu, C., \& Allan, R. P. Salinity changes in the world ocean since 1950 in relation to changing surface freshwater fluxes. Climate Dynamics, 43(3-4), 709-736. doi: 10.1007/ s00382-014-2131-7

Somavilla, R., Gonzalez-Pola, C., , \& Fernandez-Diaz, J. (2017). The warmer the ocean surface, the shallower the mixed layer. how much of this is true? Journal of Geophysical Research, 122(9), 7698-7716. doi: 10.1002/2017JC013125

Sverdrup, H. (1953, 01). On conditions for the vernal blooming of phytoplankton. $J$. Cons. int. Explor. Mer, 18, 287-295. doi: 10.1093/icesjms/18.3.287

Thorpe, S. A. (2005). The turbulent ocean. Cambridge University Press.

Turner, J. $(1967,10)$. Salt fingers across a density interface. Deep Sea Research and Oceanographic Abstracts, 14, 599-611. doi: 10.1016/0011-7471(67)90066-6

Turner, J. (1973, 01). Buoyancy effects in fluids. doi: $10.1017 /$ CBO9780511608827

Turner, J. (1983). Oceanic fine and microstructure. Brewer P.G. (eds) Oceanography.

Vladoiu, A., Bouruet-Aubertot, P., Cuypers, Y., Ferron, B., Schroeder, K., Borghini, M., ... Ben Ismail, S. $\quad(2018,05)$. Turbulence in the sicily channel from microstructure measurements. Deep Sea Research Part I: Oceanographic Research Papers. doi: 10.1016/j.dsr.2018.05.006

Volosciuk, C., Maraun, D., Semenov, V. A., Tilinina, N., Gulev, S. K., , \& Latif, M. (2016). Rising mediterranean sea surface temperatures amplify extreme summer precipitation in central europe. $\quad$ Scientific Reports, 6(32450). doi: $10.1038 /$ srep32450

Wheeler, J. D., Secchi, E., Rusconi, R., , \& Stocker, R. (2019). Not just going with the flow: The effects of fluid flow on bacteria and plankton. The Annual Review of Cell and Developmental Biology.

Wihsgotta, J. U., Sharples, J., Hopkins, J. E., Woodward, E. M. S., Hulld, T., Greenwood, N., ... Sivyer, D. B. (2019). Observations of vertical mixing in autumn and its e ect on the autumn phytoplankton bloom. Progress in Oceanography, 177 .

Wolk, F., Yamazaki, H., Seuront, L., \& Lueck, R. (2002, 05). A new free-fall profiler for measuring biophysical microstructure. Journal of Atmospheric and Oceanic Technology, 19. doi: 10.1175/1520-0426(2002)019<0780:ANFFPF $\rangle$ 2.0.CO;2

Woodson, C. $(2018,01)$. The fate and impact of internal waves in nearshore ecosystems. Annual Review of Marine Science, 10. doi: 10.1146/annurev-marine-121916 $-063619$

Wunsch, C., \& Ferrari, R. (2004). Vertical mixing, energy, and the general circulation of the oceans. Annual Review of Fluid Mechanics, 36, 281-314.

Xie, X., \& Li, M. (2019, 04). Generation of internal lee waves by lateral circulation in a coastal plain estuary. Journal of Physical Oceanography, 49. doi: 10.1175/ JPO-D-18-0142.1

Zhang, H.-M., \& Talley, L. $\quad(1998,10) . \quad$ Heat and buoyancy budgets and mixing rates in the upper thermocline of the indian and global oceans. Journal of Physical Oceanography, 28, 1961-1978. doi: 10.1175/1520-0485(1998)028<1961: HABBAM $>2.0 . \mathrm{CO} ; 2$

Zhang, W., Villarini, G., Scoccimarro, E., \& Napolitano, F. (2020, 05). Examining the precipitation associated with medicanes in the high-resolution era-5 reanalysis 
data. International Journal of Climatology. doi: 10.1002/joc.6669

Zika, J. D., Skliris, N., Nurser, A. J. G., Josey, S. A., Mudryk, L., Laliberte, F., \& Marsh, R. (2015). Maintenance and broadening of the ocean's salinity distribution by the water cycle. Journal of Climate, 28(24), 9550-9560. doi: 10.1175/JCLI-D-15-0273.1

Zingone, A., D’Alelio, D., Mazzocchi, M. G., Montresor, M., \& Sarno, D. 05). Time series and beyond: Multifaceted plankton research at a marine mediterranean lter site. Nature Conservation, 34, 273-310. doi: 10.3897/

${ }_{917} \quad$ mediterranean lter site. 


\section{Supporting Information for "Microstructure observations of the summer-to-winter destratification at a coastal site in the Gulf of Naples"}

Florian Kokoszka $^{1}$, Fabio Conversano ${ }^{1}$, Daniele Iudicone ${ }^{1}$, Bruno Ferron ${ }^{2}$,

Pascale Bouruet-Aubertot ${ }^{3}$, Justine Mc Millan ${ }^{4}$

${ }^{1}$ Stazione Zoologica Anton Dohrn, Naples, Italy

${ }^{2}$ Univ. Brest, CNRS, IFREMER, IRD, Laboratoire d'Océanographie Physique et Spatiale (LOPS), IUEM, Plouzané, France

${ }^{3}$ Sorbonne Université (UPMC, Univ Paris 06)-CNRS-IRD-MNHN, LOCEAN, Paris, France

${ }^{4}$ Rockland Scientific International Inc., Victoria, Canada

\section{Contents of this file}

1. Text for supplementary tables S1 and S2

2. Text for supplementary figures S1 to S5

3. Table S1 and S2

4. Figures $\mathrm{S} 1$ to $\mathrm{S} 5$

Introduction We provide in Tab. S1 the list and dates of the CTD casts (referenced as MC), including the sequence of VMP profiles. Statistics of the Turners's regimes by layers

Corresponding author: F. Kokoszka, Department of Research Infrastructures for Marine Biological Resources (RIMAR), Stazione Zoologica A. Dohrn, villa Comunale, 80121, Naples, Italy (florian.kokoszka@szn.it) 


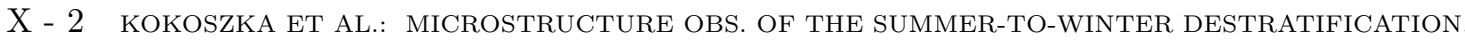

are given in Tab. S2. We provide in Fig. S1 some details of the VMP data processing. The stratification's decomposition through baroclinic modes of internal waves is presented in Fig. S2. Vertical profiles of some MC casts for CTD and VMP data are detailed in Fig. S3. Additional statistics of the $S h_{L P}$ are presented in Fig. S4 and Fig. S5.

Tab S1. Metadata We present in Tab. S1 the dates and references of CTD and VMP profiles.

Tab S2. Turner's regimes We present in Tab. S2 some statistics from the Turner's analysis.

Fig S1. VMP processing We calculated dissipation rates of turbulent kinetic energy with the ODAS Toolbox provided by Rockland (version 4.4.06). We present on Fig. S1 the quality metric of our data with the Figure of Merit (FM) and two examples of Nasmyth's fit illustrating stratified and weakly stratified water-column cases.

Fig S2. Stratification and baroclinic modes of internal waves Ocean dynamic vertical modes were calculated for each profile from $N^{2}$, using the routine from Klink (1999). Profiles were smoothed by filtering over a 10m-length running window before applying the algorithm. We focused then on the two first modes B1 and B2 that presented the largest variances. We defined then some vertical envelopes for the layers of these two modes. For each profile, we considered the layer containing the shear maxima of the first two baroclinic modes. To achieve this, we normalized the shear maxima to 1 and identified the depths interval, as the upper and lower depths of the layer where values were $>0.9$. To consider only stratified part of the water-column, calculations were made below the MLD. A comparison between $N^{2}$ calculated from both VMP-microCT and CTD hydrology, with a plot of the baroclinic modes and their envelope is shown on Fig. S2. 
Fig S3. VMP casts's examples We present on Fig. S3 vertical profiles from the VMP casts MC1173, MC1175 and MC1180 to show some examples of the rich structure of the water-column. Cast MC1180 illustrates a winter case when the MLD reaches the proximity of the bottom layer, where a turbid feature is present from 62 to $70 \mathrm{~m}$. In the stratified cases of casts MC1173 and MC1175, even more thin, turbid bottom layers are present too below $60 \mathrm{~m}$. Weak double salt fingering layers can be seen too, below the MLD between 25 and $45 \mathrm{~m}$, with $T u$ angles around $60^{\circ}$ and $50^{\circ}$, respectively. All casts show intensified $S h_{L P}$ located below the passage of the local density gradients.

Fig S4. Probability density functions of the low-frequency content of the micro-structure shear The stratified layers possibly containing internal wave activity were remarkably co-located with the low-passed energy component $S h_{L P}$ (see Appendix) that could be an interesting proxy of energetic motions, even its values are not possible to interpret. A clear pattern is visible (see Fig. A1), with intense occurrences distributed into the highly stratified layers during the summer period, and then into the subsurface layers marking the baroclinic modes $B 1$ and $B 2$. Two tendencies are visible. A first one below the MLD and B1 in July and early August, and a second one through both B1 and B2 layers from mid-August to the end of October. In terms of distribution (Fig. S4), the most intense values of around $1 \times 10^{-3} \mathrm{~s}^{-2}$ are contained into the bins below the MLD in the B1 bin (Fig. S4.b). Surface layers are dominated by weaker values of around $6 \times 10^{-2}$ $\mathrm{s}^{-2}$ (Fig. S4.a).

Fig S5. Dissipation rates in function of $N^{2}$ and $S h_{L P}$ Even $S h_{L P}$ is challenging to use and interpret, a classical display averaged values of $\epsilon\left(W \cdot \mathrm{kg}^{-1}\right)$ by intervals $\Delta N^{2}$ $\left(s^{-2}\right)$ and $\Delta S h_{L P}\left(s^{-2}\right)$ is shown on Fig. S5. 
X - 4 KOKOSZKA ET AL.: MiCRostruCtURE OBS. OF THE SUMMER-TO-WINTER DESTRATIFiCATION.

Table S1. General information of the MC-CTD casts and VMP profiles.

\begin{tabular}{|c|c|c|c|c|c|c|c|c|}
\hline VMP\# & $\begin{array}{l}\text { CTD\# } \\
\text { (MC cast) }\end{array}$ & Date & VMP\# & $\begin{array}{l}\text { CTD\# } \\
\text { (MC cast) }\end{array}$ & Date & VMP\# & $\begin{array}{l}\text { CTD\# } \\
\text { (MC cast) }\end{array}$ & Date \\
\hline 1 & 1160 & 07/07/2015 08:01 & 24 & 1168 & 01/09/2015 07:46 & 47 & 1176 & 03/11/2015 09:31 \\
\hline 2 & 1161 & 15/07/2015 09:39 & 25 & 1168 & 01/09/2015 08:40 & 48 & 1177 & 10/11/2015 09:24 \\
\hline 3 & 1161 & 15/07/2015 09:41 & 26 & 1168 & 01/09/2015 08:43 & 49 & 1177 & 10/11/2015 09:27 \\
\hline 4 & 1162 & 21/07/2015 08:04 & 27 & 1169 & 08/09/2015 07:57 & 50 & 1178 & 18/11/2015 09:23 \\
\hline 5 & 1162 & 21/07/2015 08:07 & 28 & 1169 & 08/09/2015 08:00 & 51 & 1178 & 18/11/2015 09:25 \\
\hline 6 & 1162 & $21 / 07 / 201508: 55$ & 29 & 1169 & 10/09/2015 08:46 & 52 & 1179 & 24/11/2015 09:49 \\
\hline 7 & 1163 & 28/07/2015 08:23 & 30 & 1170 & $16 / 09 / 201508: 27$ & 53 & 1179 & $24 / 11 / 2015$ 09:52 \\
\hline 8 & 1163 & 28/07/2015 09:26 & 31 & 1170 & 16/09/2015 08:30 & 54 & 1180 & 01/12/2015 09:08 \\
\hline 9 & 1163 & 28/07/2015 09:29 & 32 & 1170 & $16 / 09 / 2015 \quad 10: 18$ & 55 & 1180 & 01/12/2015 09:11 \\
\hline 10 & 1163 & 28/07/2015 08:20 & 33 & 1170 & 16/09/2015 10:21 & 56 & 1181 & 09/12/2015 09:27 \\
\hline 11 & 1164 & 04/08/2015 07:49 & 34 & 1171 & $22 / 09 / 201507: 55$ & 57 & 1181 & 09/12/2015 09:30 \\
\hline 12 & 1164 & 04/08/2015 07:51 & 35 & 1171 & $22 / 09 / 201507: 58$ & 58 & 1182 & 15/12/2015 09:32 \\
\hline 13 & 1164 & 04/08/2015 08:45 & 36 & 1171 & 22/09/2015 08:53 & 59 & 1182 & $15 / 12 / 201509: 35$ \\
\hline 14 & 1164 & 04/08/2015 08:48 & 37 & 1171 & $22 / 09 / 2015$ 08:56 & 60 & 1183 & 22/12/2015 09:01 \\
\hline 15 & 1165 & $11 / 08 / 201508: 11$ & 38 & 1172 & 08/10/2015 08:38 & 61 & 1183 & 22/12/2015 09:04 \\
\hline 16 & 1165 & 11/08/2015 08:14 & 39 & 1172 & 08/10/2015 08:40 & 62 & 1184 & 29/12/2015 09:01 \\
\hline 17 & 1166 & 18/08/2015 07:55 & 40 & 1173 & 13/10/2015 08:21 & 63 & 1184 & 29/12/2015 09:04 \\
\hline 18 & 1166 & $18 / 08 / 201507: 58$ & 41 & 1173 & 13/10/2015 08:24 & 64 & 1186 & 19/01/2016 08:36 \\
\hline 19 & 1167 & 26/08/2015 07:34 & 42 & 1174 & 22/10/2015 08:09 & 65 & 1186 & 19/01/2016 08:39 \\
\hline 20 & 1167 & 26/08/2015 07:37 & 43 & 1174 & $22 / 10 / 201508: 12$ & 66 & 1187 & 26/01/2016 09:59 \\
\hline 21 & 1167 & 26/08/2015 08:59 & 44 & 1175 & $27 / 10 / 2015$ 09:34 & 67 & 1187 & $26 / 01 / 201610: 02$ \\
\hline 22 & 1167 & 26/08/2015 09:02 & 45 & 1175 & $27 / 10 / 2015$ 09:37 & 68 & 1188 & 02/02/2016 11:29 \\
\hline 23 & 1168 & 01/09/2015 07:44 & 46 & 1176 & 03/11/2015 09:28 & $\begin{array}{l}69 \\
70 \\
71\end{array}$ & $\begin{array}{l}1188 \\
1190 \\
1190\end{array}$ & $\begin{array}{l}02 / 02 / 2016 \quad 11: 32 \\
23 / 02 / 2016 \quad 10: 19 \\
23 / 02 / 2016 \quad 10: 22\end{array}$ \\
\hline
\end{tabular}


Table S2. (a) Decibar occupation of the Turner's regimes for the whole dataset. (b) Statistics by layers and period bins for the double diffusive and (c) diffusive convection regimes.

(a) General

\begin{tabular}{|l|l|l|l|l|l|}
\hline Regime & SF & Stable & Diffusive & Instable & All \\
\hline Count & 1202 & 2159 & 396 & 142 & 3899 \\
$\%$ & $30.8 \%$ & $55.4 \%$ & $10.2 \%$ & $3.6 \%$ & 100 \\
\hline
\end{tabular}

(b) Double diffusive regime (salt fingers)

\begin{tabular}{|ll|lll|llll|l|}
\hline Bin & $\%$ & $\begin{array}{l}\text { mean } T u \\
\text { mean } R_{\rho}\end{array}$ & median & std & SF\% & Stable\% & Diff.\% & Inst.\% & Bin count \\
\hline All & 100 & $54.7(T u)$ & 51.8 & 9.3 & 30.80 & 55.4 & 10.2 & 3.6 & 3899 \\
& & $8.88\left(R_{\rho}\right)$ & 6.79 & 6.82 & & & & & \\
\hline surface-MLD & 32 & 60.5 & 58.7 & 11.2 & 24.7 & 41.8 & 25 & 8.5 & 1573 \\
& & 6.03 & 3.77 & 5.67 & & & & & \\
\hline MLD-bottom & 68 & 52.1 & 50.2 & 6.61 & 35 & 64.6 & 0.1 & 0.3 & 2326 \\
& & 10.4 & 8.36 & 6.89 & & & & & \\
\hline W1 & 13 & 59.8 & 58.7 & 10.4 & 28.1 & 46.2 & 22.7 & 3 & 572 \\
& & 6.07 & 3.88 & 5.54 & & & & & \\
\hline W2 & 19 & 61.0 & 58.4 & 11.8 & 22.8 & 39.3 & 26.3 & 11.7 & 1001 \\
& & 6.01 & 3.69 & 5.77 & & & & & \\
\hline B1 & 39 & 51.5 & 50.3 & 5.34 & 59.9 & 39.3 & 0.4 & 0.4 & 778 \\
& & 10.5 & 8.57 & 6.59 & & & & & \\
\hline B2 & 13 & 53.4 & 50.5 & 8.97 & 29.6 & 69.5 & 0 & 0.9 & 544 \\
& & 10.1 & 7.82 & 7.67 & & & & & \\
\hline BBL & 6 & 55.02 & 52.4 & 8.46 & 8.8 & 90.9 & 0.2 & 0 & 803 \\
& & 8.67 & 5.79 & 6.43 & & & & & \\
\hline
\end{tabular}

(c) Diffusive regime (convection)

\begin{tabular}{|ll|lll|llll|l|}
\hline Bin & $\%$ & $\begin{array}{l}\text { mean } T u \\
\text { mean } R_{\rho}\end{array}$ & median & std & SF\% & Stable\% & Diff.\% & Inst.\% & Bin count \\
\hline All & 100 & $-67.4(T u)$ & -67.9 & 11.9 & 30.8 & 55.4 & 10. & 3.6 & 3899 \\
& & $0.43\left(R_{\rho}\right)$ & 0.42 & 0.25 & & & & & \\
\hline surface-MLD & 99 & -67.57 & -68.1 & 11.8 & 24.7 & 41.8 & 25 & 8.5 & 1573 \\
& & 0.43 & 0.42 & 0.25 & & & & & \\
\hline MLD-bottom & 1 & -49.3 & -49.1 & 3.4 & 35 & 64.6 & 0.1 & 0.3 & 2326 \\
& & 0.07 & 0.07 & 0.06 & & & & & \\
\hline W1 & 33 & -63.6 & -63.0 & 10.04 & 28.1 & 46.2 & 22.7 & 3 & 572 \\
& & 0.35 & 0.32 & 0.20 & & & & & \\
\hline W2 & 66 & -69.50 & -71.25 & 12.21 & 22.80 & 39.30 & 26.30 & 11.70 & 1001 \\
& & 0.48 & 0.49 & 0.26 & & & & & \\
\hline B1 & 1 & -66.8 & -76.2 & 17.6 & 59.9 & 39.3 & 0.4 & 0.4 & 778 \\
& & 0.42 & 0.60 & 0.34 & & & & & \\
\hline B2 & 0 & NaN & NaN & NaN & 29.6 & 69.5 & 0 & 0.9 & 544 \\
& 1 & -47.6 & -47.6 & 2.14 & 8.8 & 90.9 & 0.2 & 0 & 803 \\
\hline BBL & & 0.04 & 0.04 & 0.03 & & & & & \\
& & & & & & & & & \\
\hline
\end{tabular}



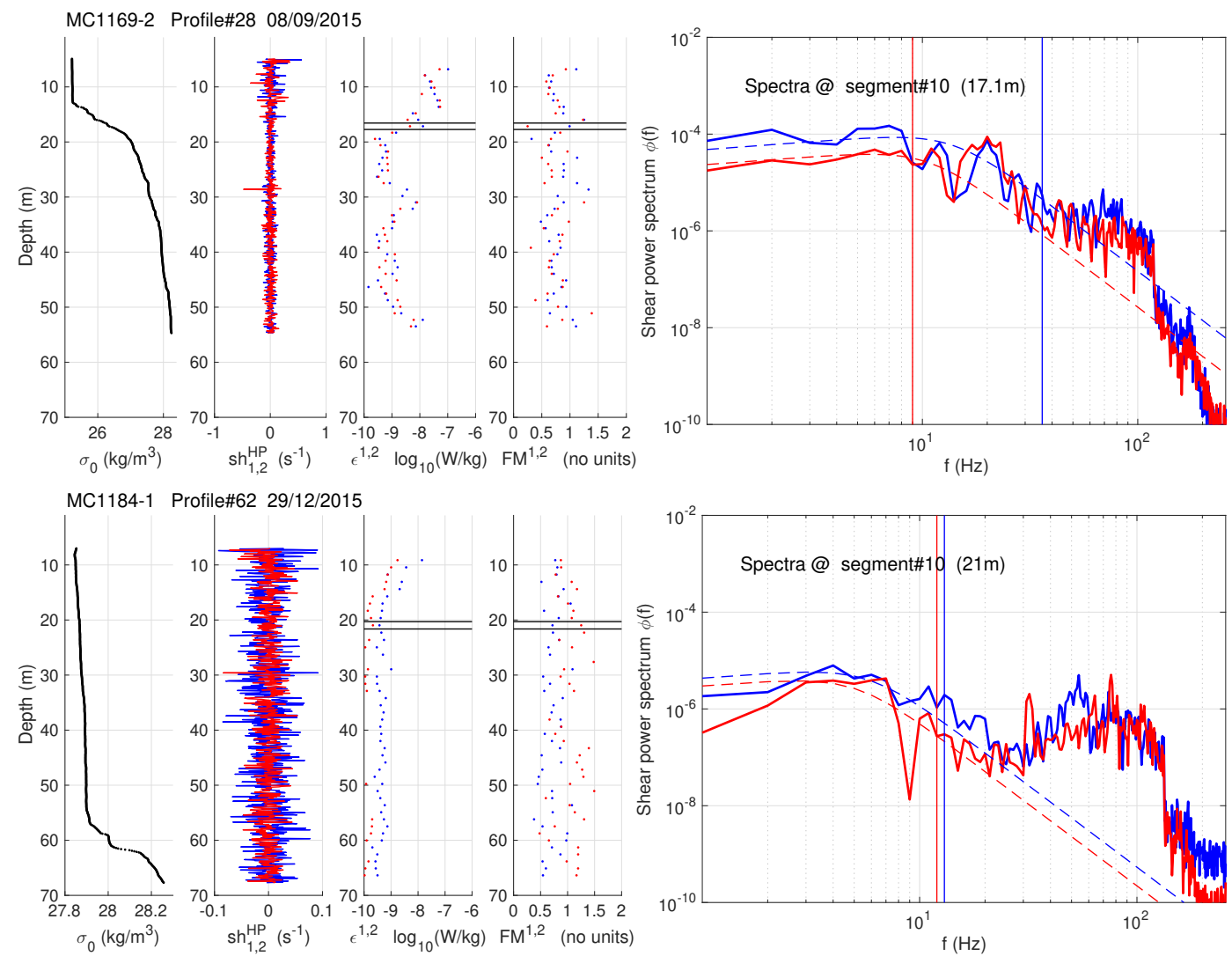

Figure S1. Examples of Nasmyth's spectra fits, for stratified (top) and weakly stratified cases (bottom). The final $\epsilon$ is the mean value of the individual estimates $\epsilon_{1}$ and $\epsilon_{2}$, excepted for the case where only one value is available (for example after rejection if $F M>1.5$ ). Finally, if two estimates differ by one order of magnitude, the lowest is kept. 


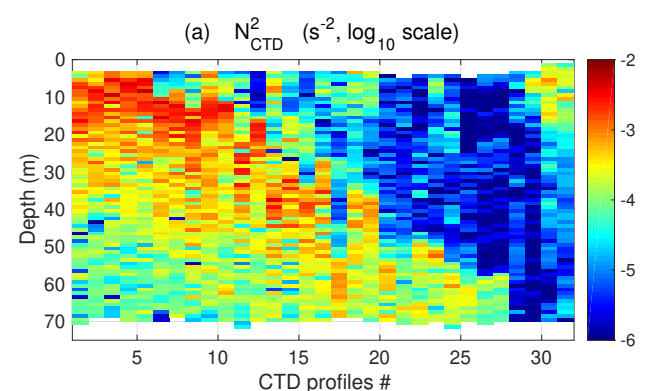

(c) Baroclinic mode 1 (B1): Vertical velocity structure (abs. value)

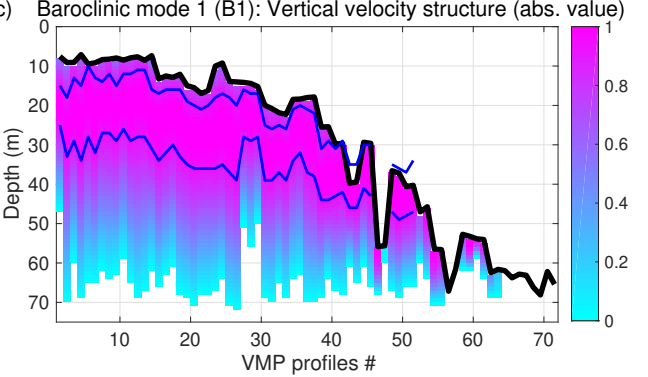

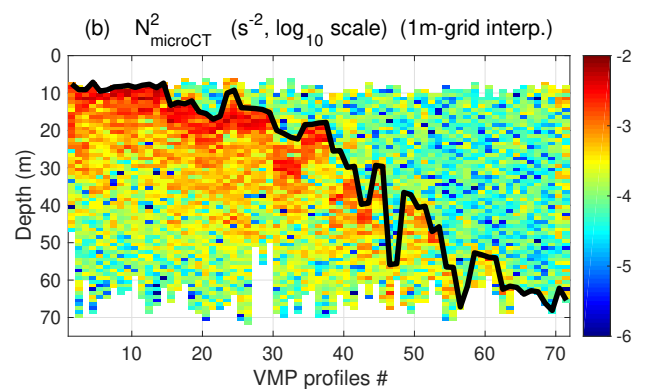

(d) Baroclinic mode 2 (B2): Vertical velocity structure (abs. value)

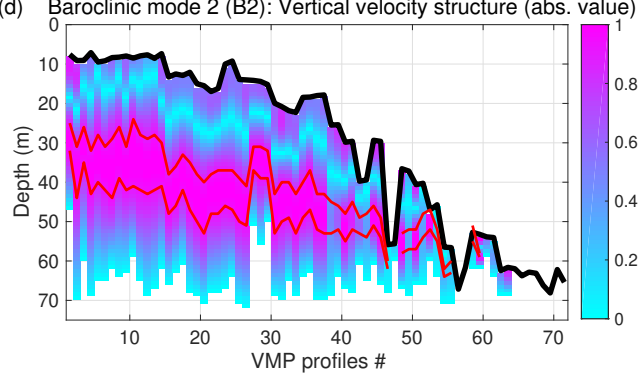

Figure S2. (a) Profiles of the Brunt-Väisälä frequency $N_{c t d}^{2}\left(\mathrm{~s}^{-2}\right)$ computed from the hydrology obtained with the CTD Seabird $911+$ and (b) $N_{v m p}^{2}\left(\mathrm{~s}^{-2}\right)$ computed from the hydrology obtained with the micro-CT nose-mounted on the VMP-250. Both quantities have been calculated with the dedicated Gibbs Seawater function. $M L D_{0.4^{\circ}}^{\theta}$ is shown In thick black. (c) Vertical velocity structure (non-dimensional) of the first and (d) second baroclinic modes calculated from $N_{v m p}^{2}$. $M L D_{\theta_{0}}^{0.4^{\circ} \mathrm{C}}$ (thick black line), region of maximum energy of baroclinic mode 1 (between blue lines) and mode 2 (between red lines). 


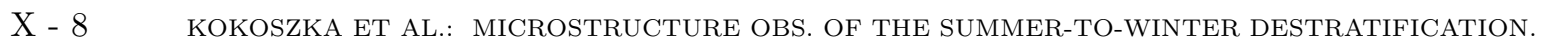
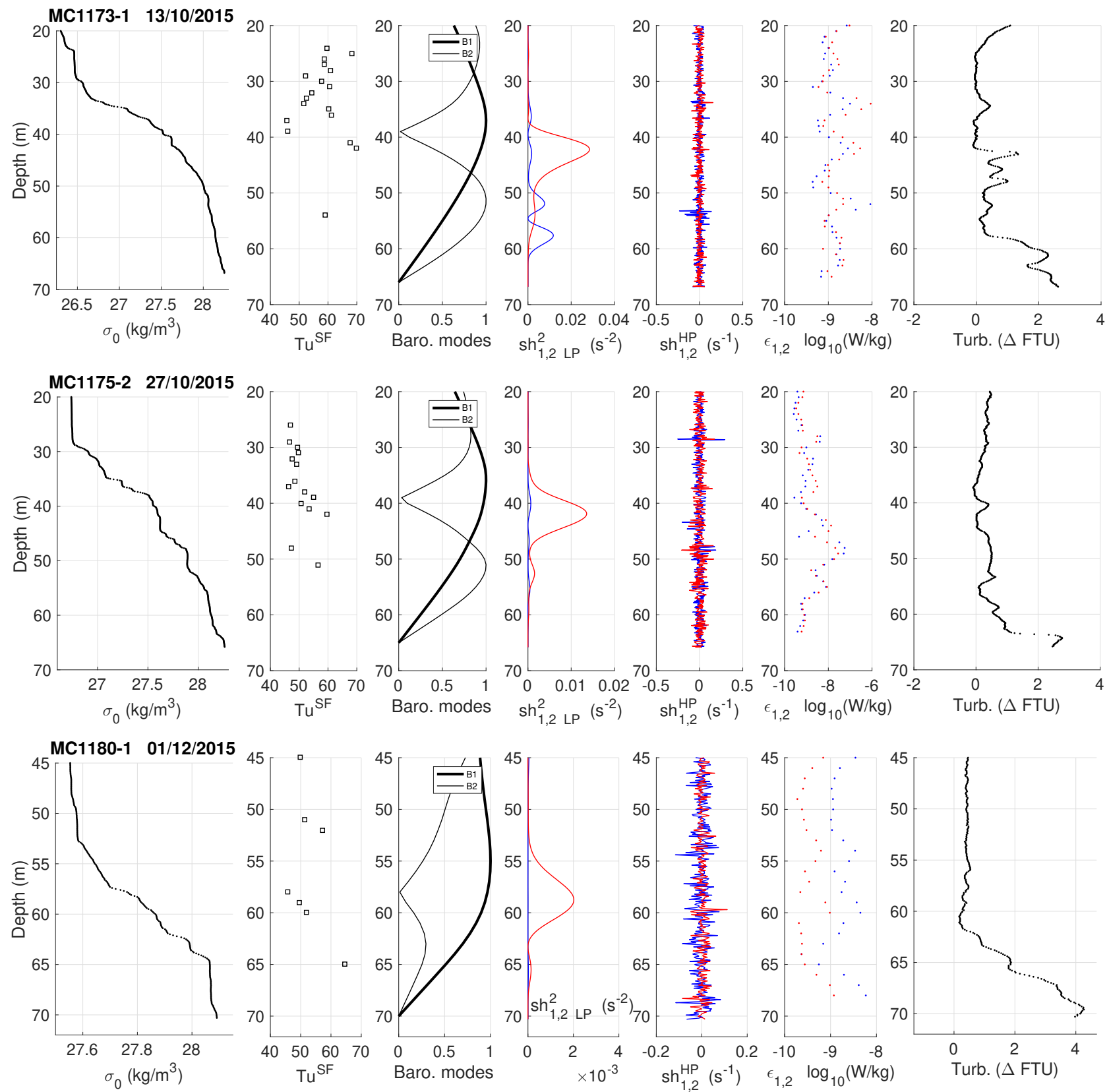

Figure S3. Top to bottom : profiles from the VMP casts MC1173, MC1175 and MC1180. From left to right : $\sigma_{0}\left(\mathrm{~kg} \mathrm{~m}^{-3}\right)$, Turner angles $\left(^{\circ}\right)$ into the salt-fingering regime, first and second vertical baroclinic modes (non-dimensional), low-passed energy shears $S h_{L P}\left(\mathrm{~s}^{-2}\right)$, hi-passed shears $\left(\mathrm{s}^{-1}\right)$ used to estimate $\epsilon\left(\mathrm{W} \mathrm{kg}^{-1}\right)$, and turbidity ( $\Delta \mathrm{FTU}$, offset from the reference value -2.5). For shears and $\epsilon$, blue and red refers to the respective shear probes 1 and 2 . 
(a)

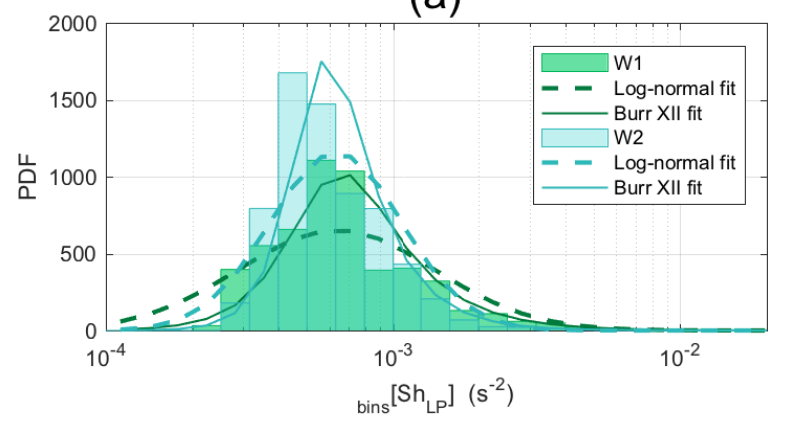

(b)

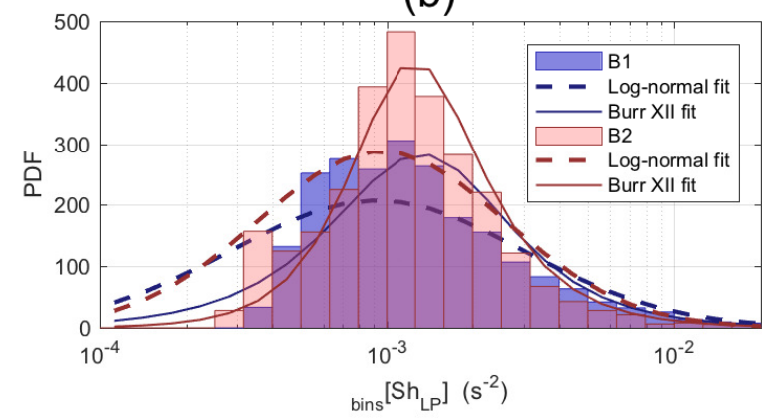

(c)

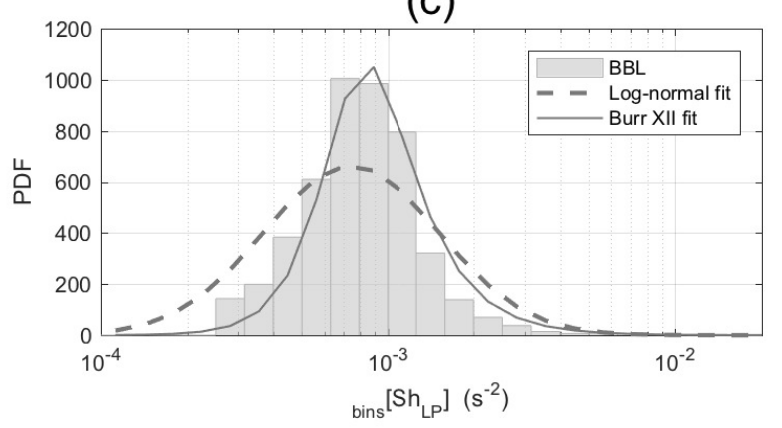

Figure S4. Pdfs of $S h_{L P}$ i.e. $\left\langle\left(\partial_{z} u\right)^{2}\right\rangle_{L P}^{3 m}\left(\mathrm{~s}^{-2}\right)$ through (a) temporal bins $\mathrm{W} 1$ and $\mathrm{W} 2$, and $(\mathrm{b}, \mathrm{c})$ vertical bins B1, B2 and BBL. The fits of the log-normal and Burr type XII distributions are indicated with the dashed and solid lines, respectively. 
(a)

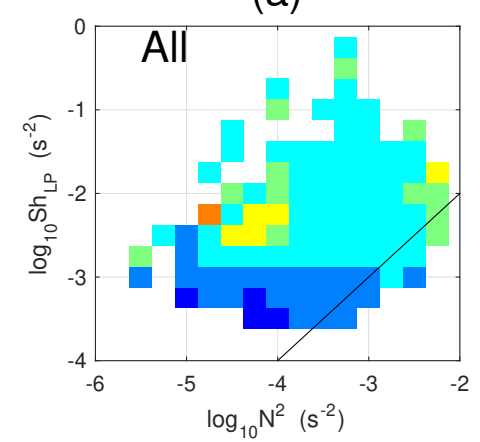

(d)

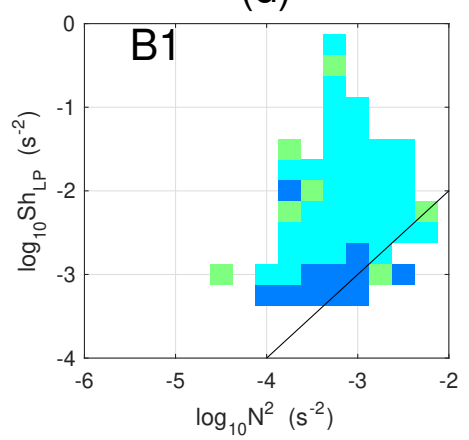

(b)

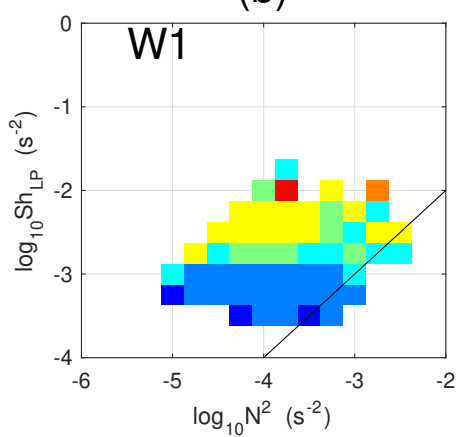

(e)

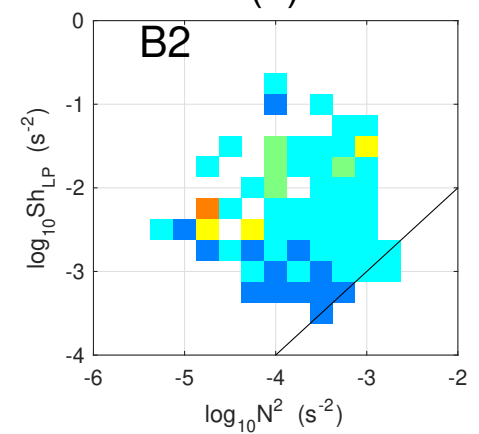

(c)

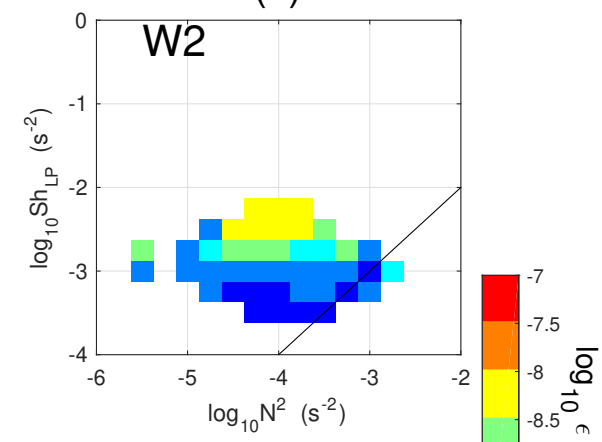

(f)

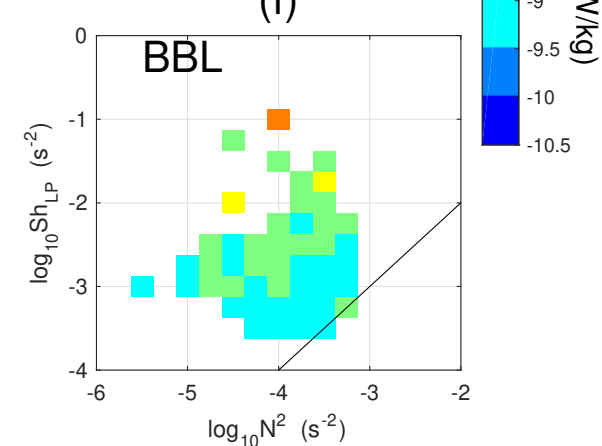

Figure S5. Averaged values of $\epsilon\left(W . k g^{-1}\right)$ by intervals $\Delta N^{2}\left(s^{-2}\right)$ and $\Delta S h_{L P}\left(s^{-2}\right)$, for the different groups of periods and layers. Intervals $\Delta N^{2}$ and $\Delta S h_{L P}$ have been defined $=0.25$ in the logarithmic domain $\left(\log _{10}\right)$. Black line indicates $\frac{N^{2}}{S h_{L P}}=1$. 